\title{
HORMONAL CONTROL OF CELL FORM AND NUMBER IN THE ZEBRA FINCH SONG SYSTEM ${ }^{1}$
}

\author{
MARK E. GURNEY²
}

Division of Biology, California Institute of Technology, Pasadena, California 91125

\begin{abstract}
Administration of testosterone (T), $17 \beta$-estradiol $\left(\mathrm{E}_{2}\right)$, or $5 \alpha$-dihydrotestosterone (DHT) to female zebra finch chicks (Poephila guttata) at hatching exerts effects on brain sexual differentiation. Within a telencephalic station (the nucleus robustus archistriatalis, RA) of the neural pathway which participates in the efferent control of song, masculinization of several indices of neuronal size is induced by exposure to $\mathrm{T}$ or $\mathrm{E}_{2}$. Within $\mathrm{RA}$, a sensitive assay of a single neuron's sexually differentiated state is the diameter of its soma. By this criteria, all of the neurons within RA can be masculinized with a sufficient dose of $T$. As the dose of $T$ is progressively decreased, the proportion of RA neurons which undergo the transition from female to male falls, while the magnitude of the change in soma size remains basically unaltered. Administration of T or DHT masculinizes the number of neurons in RA.
\end{abstract}

The agents, internal or external, soluble or bound, molecular or ionic, which take neuroepithelial cells out of division, direct their migration from the germinal zone, and instruct elaboration of a dendritic arborization, acceptance of afferents, transmitter and receptor choices, axonal outgrowth and efferent target, and maintenance or death, are largely unknown. Considerable progress has been made in the identification of soluble factors which influence the differentiation of neurons within peripheral ganglia, primarily because of their accessibility to study in vitro. A factor permissive for the maintenance in culture of sympathetic neurons (nerve growth factor) has been identified (Levi-Montalcini and Angeletti, 1968) and shown to influence the elaboration (Green and Tischler, 1976) and growth of neuritic processes (Campenot, 1977; Letourneau, 1978; Menesini-Chen et al., 1978). Other soluble factors seem to play a role in the commitment of peripheral neurons to specific patterns of neurotransmitter metabolism (Patterson and Chun, 1977; Mudge, 1979).

Less is known about the cellular consequences of factors which act centrally in the nervous system during

\footnotetext{
${ }^{1}$ This project was supported by National Institutes of Health Grant HD10501 to M. Konishi, as well as by National Institutes of Health Training Grant GM0086 and Grant HD05940, The Arthur McCallum Fund, and the Spencer Foundation. Some of the Golgi-Cox material was kindly provided by S. O. Ebbeson or by E. Akutagawa. J. Brockes, J. Myerson, D. Kelley, and A. Arnold all provided valuable advice throughout the course of this work, and F. Nottebohm kindly commented upon the manuscript. I am especially grateful to M. Konishi for his suggestion that I undertake this study.

${ }^{2}$ Current address: MRC Neuroimmunology Project, Department of Zoology, University College London, Gower Street, London WC1E 6BT, England.
}

development. Early exposure to gonadal hormones profoundly alters the later expression of sexual behavior, the functional differentiation of the hypothalamo-pituitary axis, and sex-specific patterns of aggressive, feeding, and parental behaviors (see reviews in Goy and McEwen, 1980). These effects have been taken as the outward sign of hormone-dependent changes in the differentiation of the neural circuits which underlie sexually dimorphic brain functions (Phoenix et al., 1959). The work of ToranAllerand (1976) suggests that androgens or estrogens do act directly on brain lissue, and some progress has been made at identifying central consequences of their action (Caleresu and Henry, 1971; Raisman and Field, 1973; Dyer et al., 1976; Greenough et al., 1977; Gorski et al., 1978; Breedlove and Arnold, 1980). Despite the wide diversity in the behavioral expression of brain sexual differentiation, an underlying hope remains that logically simple effects upon neuronal development, common to different types of neurons, will translate into the complex varieties of behavioral or physiological consequences of hormone action which are observed.

The masculinization of song and of its neural substrate in the zebra finch (Poephila guttata) offers a valuable opportunity to relate the cellular consequences of hormone action directly to the sexual differentiation of behavior (Gurney and Konishi, 1980). Only the male zebra finch normally sings. The male's song is androgen dependent (Pröve, 1974, 1978; M. E. Gurney, submitted for publication), but the female is behaviorally insensitive to that hormone (Arnold, 1974; Gurney, 1981). The qualitative sex difference in song behavior mirrors morphological differences in the neural pathway for the efferent control of song (Nottebohm and Arnold, 1976). This 
paper considers in detail the cellular consequences of testosterone (T), ${ }^{3} 5 \alpha$-dihydrotestosterone (DHT), and $17 \beta$-estradiol $\left(\mathrm{E}_{2}\right)$ action at hatching.

The song system includes two telencephalic nuclei, the nucleus hyperstriatum ventrale, pars caudale ( $\mathrm{HVc}$ ) and the nucleus robustus archistriatalis (RA), whose lesion disrupts song in adult male canaries (Nottebohm et al., 1976). HVc is afferent to RA, and RA has two efferent projections onto lower brain centers. One is onto the dorsomedial intercollicular nucleus (DM)/nucleus intercollicularis (ICO) complex, and the other is onto the tracheosyringeal portion of the hypoglossal nucleus (nXIIts). DM also projects to nXIIts, and the motor neurons of nXIIts directly innervate the avian vocal organ, the syrinx. All of these nuclei are larger in male zebra finches than in females (Nottebohm and Arnold, 1976). Exposure to $E_{2}$ at hatching masculinizes the cytoarchitecture of RA and HVc in females, and subsequently, they are able to sing when exposed to androgen as adults (Gurney and Konishi, 1980). The focus of this paper is on the cellular consequences of hormone action in RA.

\section{Materials and Methods}

Golgi impregnation. Whole brains were processed for Golgi-Cox by the slow procedure with optional counterstaining described by Ramon-Moliner (1970). All individuals were adult ( $>90$ days of age), gonadally intact, and in breeding condition when killed with an overdose of Nembutal. The brains were impregnated for 3 weeks in a mercuric chloride/potassium dichromate solution, dehydrated, embedded in parlodion, sectioned in either the sagittal or coronal plane at a thickness of $120 \mu \mathrm{m}$, and then alkalinized on the slide after mounting. Alternate sections were counterstained with cresyl violet. Ten female and six male brains were processed for Golgi-Cox; of these, six of the female and four of the male brains contained well impregnated examples of RA neurons and were selected for analysis. For Golgi-rapid, birds were perfused with $4 \%$ formalin buffered in $0.13 \mathrm{M}$ sodium phosphate ( $\mathrm{pH} 7.2$ ). Brains were impregnated as described by Lund (1973). Then they were embedded in parlodion and sectioned in the coronal plane at a thickness of $90 \mu \mathrm{m}$. Five male brains were selected for analysis. Two-dimensional drawings of impregnated neurons were prepared with the aid of a drawing tube through a $\times 40$ dry objective at a final magnification of $\times 400$. A modi-

\footnotetext{
${ }^{3}$ The biochemical abbreviations used are: DHT, $5 \alpha$-dihydrotestosterone; $\mathbf{E}_{2}, 17 \beta$-estradiol; $T$, testosterone. The neuroanatomical abbreviations used are: $\mathrm{A}$, archistriatum; DM, dorsomedial intercollicular nucleus; E, ectostriatum; HV, hyperstriatum ventrale; $\mathrm{HVc}$, hyperstriatum ventrale, pars caudale; ICO, nucleus intercollicularis; IO, nucleus olivaris inferior; LAD, lamina archistriatalis dorsalis; LH, lamina hyperstriatica; LMD, lamina medullaris dorsalis; LPO, lobus parolfactorius; LRF, formatio reticularis lateralis mesencephali; MAN, magnocellular nucleus of the anterior neostriatum; MLd, nucleus mesencephalicus, pars dorsalis; NA, neostriatum anterior; NC, neostriatum caudale; NF, neostriatum frontale; NI, neostriatum intermedium; nXII, nucleus nervi hypoglossi; nXIIln, nucleus nervi hypoglossi, pars lingualis; nXIIts, nucleus nervi hypoglossi, pars tracheosyringealis; $\mathrm{OM}$, tractus occipitomesencephalicus; PA, paleostriatum augmentatum; PTN, nucleus pretectalis; RA, nucleus robustus archistriatalis; SpM, nucleus spiriformis medialis; $\mathrm{TeO}$, optic tectum; $\mathrm{X}$, area $\mathrm{X}$.
}

fication of Sholl's (1954) method was used to represent the radial distribution of dendrites within the neuron's dendritic field. A grid of concentric circles whose spacing equaled $10 \mu \mathrm{m}$ was centered upon the neuron's soma, and then the number of dendrites which intersected each circle was scored. The number of primary dendritic arms, the total number of branch segments, and the dendritic field volume (arbitrarily defined as the minimum volume sphere sufficient to enclose a neuron's complete dendritic tree) were scored for each neuron. Because of the small number of impregnated neurons which were obtained from each brain, to test whether differences among the samples signified population differences or variation in samples drawn from the same population, the nonparametric Kruskal-Wallis one-way analysis of variance by ranks was used to assess statistical significance (Siegel, 1956).

Neuroanatomical mapping techniques. Anterograde projections were traced using $\left[{ }^{3} \mathrm{H}\right] l$ leucine after the protocol of Cowan et al. (1972). Injections consisted of 0.5 to $1 \mu \mathrm{Ci}$ of $\left[4,5-{ }^{3} \mathrm{H}\right]$ leucine $(48 \mathrm{Ci} / \mathrm{mmol}$, New England $\mathrm{Nu}-$ clear) delivered in $40 \mathrm{nl}$ of $0.9 \%$ saline. Stereotaxic injections were made with an oil-filled, $1-\mu$ l Hamilton syringe fitted with a glass micropipette. Survival times after injection varied between 3 and 5 days. Exposure of the autoradiographs was generally 4 weeks.

Retrograde projections were traced with the enzyme horseradish peroxidase (HRP) by following the benzidine di-HCl protocol of Lynch et al. (1974) or the tetramethyl benzidine protocol of Mesulam (1978). Injections of $20 \%$ HRP (Boehringer-Mannheim grade 1) in 0.5\% potassium chloride were delivered in a volume of $40 \mathrm{nl}$. Survival times ranged from 12 to $16 \mathrm{hr}$. A fixative of $1 \%$ formalin, $1.25 \%$ glutaraldehyde buffered in $0.13 \mathrm{~m}$ sodium phosphate (pH 7.2) was used. Sections were cut at a thickness of $30 \mu \mathrm{m}$ in the sagittal plane, reacted, and counterstained with neutral red before coverslipping.

Standard histological protocol. All finches were adult (>90 days of age) and gonadally intact at the time of sacrifice. The birds were anesthetized deeply with 0.05 $\mathrm{ml}$ of Equithesin (Jensen-Salsbery Labs), killed by intracardial perfusion with $0.13 \mathrm{~m}$ sodium phosphate buffered at $\mathrm{pH} 7.2$, and then fixed with $4 \%$ formalin in the same buffer. The brain was removed from the skull immediately and subsequently post-fixed for several days in the same solution at $4^{\circ} \mathrm{C}$. It was then split sagittally and the right half was infiltrated with $30 \%$ sucrose (w/v) in $4 \%$ formalin overnight. On the following day, the brain was frozen and sectioned at $30 \mu \mathrm{m}$ in the sagittal plane. Every third section was collected in $0.13 \mathrm{M}$ sodium phosphate buffer ( $\mathrm{pH} 7.2$ ), mounted on Gatenby-subbed slides, and subsequently stained with $1 \%$ cresyl violet. Shrinkage was within $\pm 1 \%$ with this protocol.

Neuroanatomical measurements. To measure the volume of a nucleus, it was located on the section, its perimeter was traced with the aid of a microscopic drawing tube at a final magnification of $\times 100$, and its crosssectional area on each section was then determined. The volume of the nucleus was calculated from the sum of the measurements of the cross-sectional area and the interval of sampling $(90 \mu \mathrm{m})$. The perimeters of RA, DM, and nXIIts were defined by neuroanatomical tracing 
techniques as described below. The error in these measurements was estimated by comparing duplicate measurements of the volume of RA in a group of males and $\mathrm{E}_{2}$ females (11 individuals). In the first series of measurements, the average volume was $0.209 \mathrm{~mm}^{3}$ and in the second series (4 months later), the average volume was $0.200 \mathrm{~mm}^{3}$, a difference of approximately $5 \%$.

To count the number of neurons in RA or DM, an estimate of neuronal density was obtained, and from this measure, together with the volume of the nucleus, the number of neurons that it contained was calculated. The cytological criteria for distinguishing neurons from nonneuronal cells are described in the text. Nucleoli were chosen as the unit of count in $30-\mu$ m-thick frozen sections, and RA or DM neurons with more than one nucleolus were not observed. No correction was made for split nucleoli as nucleoli are likely to be displaced rather than cut when frozen sections are taken (Cammermeyer, 1967; Konigsmark, 1970). Relatively thick $30-\mu$ m frozen sections were used for these measurements in preference to $10-\mu \mathrm{m}$-thick paraffin-embedded sections as the precision for measurements of the volume of RA or DM in female material was greater with the thicker sections. The density of neurons in RA and DM was estimated by measurement of neuron number within a small volume (9.5 $\times 10^{3} \mu \mathrm{m}^{3}$ in the female at a magnification of $\times 1000$ and $114 \times 10^{3} \mu \mathrm{m}^{3}$ in the male at a magnification of $\times 400$ ). These volumes were large enough to insure that the measurements of neuron density were distributed normally (tests for kurtosis or skewness on randomly selected data sets were not statistically significant). For RA, systematic transits along the three cardinal axes did not reveal inhomogeneity in the distribution of neuronal density in two males or three females. At the outset of this study, it was decided to sample randomly at least 100 volumes in each individual. The cumulative mean and standard deviation for all of the measurements in a group of seven males was $6.0 \pm 1.8$ neurons/standard volume. From this, it can be shown that, for each male, a sample size of 100 insured that the estimate of neuronal density was accurate within $6 \%$ at a $95 \%$ confidence level. For all of the measurements in females, the cumulative mean and standard deviation was $2.1 \pm 1.1$; thus, a sample size of 100 insured that the estimate of neuronal density was accurate within $11 \%$ at a $95 \%$ confidence level. The observed relative error in the neuronal number estimates for the seven males was $6 \%$ and for the six females was $13 \%$. The magnitude of these errors was considerably less than the $200 \%$ sex difference in neuronal number (Table III). A similar analysis of the data collected for the measurement of neuronal number in DM revealed that the confidence levels for the estimates of neuronal density in DM were comparable.

The number of nXIIts neurons was counted directly. For this measurement, the cell nucleus was used as the unit of count, rather than nucleoli, because a substantial number of nXIIts motor neurons have more than one nucleolus. Usually, nXIIts appeared on four or five 30$\mu \mathrm{m}$-thick sections and total counts averaged 330 neurons. This number was multiplied by 3 since the interval of sampling was $90 \mu \mathrm{m}$.

To measure the somal diameter of RA neurons, the perimeter of their soma was traced with the aid of a drawing tube at a final magnification of $\times 1000$. As the somata of RA neurons varied from round to ovoid, somal diameter was arbitrarily defined as the diameter along its longest axis. In adult males and females, the somal diameters of RA neurons were distributed unimodally and tests for kurtosis or skewness seldom revealed departures from normality. An arbitrary sample size of 100 neurons from each individual was chosen. The cumulative mean and standard deviation for all of the male RA neurons measured was $17.8 \pm 2.3 \mu \mathrm{m}$, and from this, it can be shown that the measurement of neuronal diameter in each male was accurate within $2.5 \%$ at a confidence level of $95 \%$. For all of the female RA neurons measured, the cumulative mean and standard deviation was $8.1 \pm$ $1.3 \mu \mathrm{m}$, and thus, the measurement of neuronal diameter in each female was accurate within $3.2 \%$ at a $95 \%$ confidence level.

Hormone implants. Two styles of hormone-containing pellets were fabricated. The first held the steroid in a Silastic matrix, and the second consisted of a Silastic matrix which was formed inside of polyethylene (PE) tubing. Details concerning fabrication of the first type of pellet have been given elsewhere (Gurney and Konishi, 1980). To fabricate the PE-encased pellets, $T$ (Sigma) was mixed in a ratio of $1: 25$ (for the $13.8-\mu$ g pellets) or in a ratio of 1:6 (for the $50-\mu \mathrm{g}$ pellets) with RTV 738 Silastic (Dow-Corning). The steroid/Silastic slurry was then injected into $\mathrm{PE}$ tubing of 0.018 inch, inner diameter (B-D, PX108), and cured. Lengths of $2 \mathrm{~mm}$ were cut from the filled tubing to use as implants. Release of T only occurs from the cut ends of the PE-encased pellets. Both types of pellets delivered steroid with an exponentially decreasing rate. In adult females, the amount of $\mathrm{T}, \mathrm{DHT}$, or $\mathrm{E}_{2}$ remaining in the first type of pellet fell by one-half in $13.0,15.5$, and $80.6 \mathrm{hr}$, respectively, while the amount of $\mathrm{T}$ remaining in the PE-encased pellets fell by one-half in $41.0 \mathrm{hr}$ (Gurney, 1981; M. E. Gurney, unpublished data). Abbreviations used in the text and the implant schedules are given in Table I.

TABLE I

Description of steroid implants

\begin{tabular}{|c|c|c|c|c|}
\hline & $t_{1 / 2}$ & $C_{0}$ & Style of Pellet & Implantation Schedule \\
\hline$(50) \mathrm{E}_{2}$ & 80.6 & 50 & Silastic matrix & One pellet at hatching \\
\hline (50) DHT & 15.5 & 50 & Silastic matrix & One pellet at hatching \\
\hline (13.8/PE)T & 41.0 & 13.8 & PE encased, Silastic matrix & One pellet at hatching \\
\hline$(13.8,13.8 / \mathrm{PE}) \mathrm{T}$ & 41.0 & 13.8 & PE encased, Silastic matrix & $\begin{array}{l}\text { One pellet at hatching; removed and replaced by a second pellet } \\
\text { at } 3 \text { days }\end{array}$ \\
\hline$(50 / \mathrm{PE}) \mathrm{T}$ & 41.0 & 50 & PE encased, Silastic matrix & One pellet at hatching \\
\hline$(50) \mathrm{T}$ & 13.0 & 50 & Silastic matrix & One pellet at hatching \\
\hline
\end{tabular}




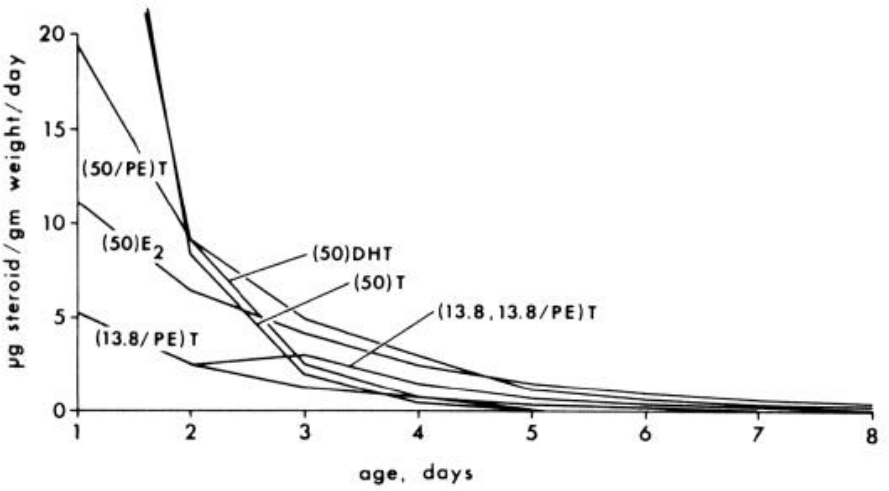

Figure 1. The (calculated) dose of steroid (micrograms/gm of body weight/day) delivered by each type of hormone implant as a function of the chick's age. Abbreviations in the figure are explained in Table I.

Details of the care of chicks were given previously (Gurney and Konishi, 1980; Gurney, 1981). On the day of hatching, each chick was implanted with a steroid-containing pellet beneath the skin over its breast muscle. Zebra finch chicks weighed $0.83 \mathrm{gm}( \pm 0.15 \mathrm{gm}, \mathrm{SD})$ at hatching and measured approximately $1.5 \mathrm{~cm}$ in length from beak to rump. By 15 days of age, their weight increased over 10 -fold. The growth of chicks between hatching and 7 days of age was determined, and this was used to estimate the dose of steroid (micrograms/gm of body weight/day) delivered by the hormone implants during this period (Fig. 1). All of the birds described in the text were killed when adult ( $>90$ days of age). Exposure to $\mathrm{T}, \mathrm{DHT}$, or $\mathrm{E}_{2}$ at hatching did not alter the mortality or sex ratio of any experimental group as compared to unimplanted controls. The gonadal sex of each bird was determined and always matched the assignment of sex based on the sexually dimorphic plumage of the zebra finch.

Adult females ( $>90$ days of age) were gonadally intact and in breeding condition when they received steroid implants. Each implant was a 2-mm length (as compared to the 1-mm lengths which were used to implant chicks) of the unencased DHT/Silastic rope and contained 100 $\mu \mathrm{g}$ of DHT. Survival time was 30 days after implantation. Adult $\mathrm{E}_{2}$ females (>90 days of age) also were intact gonadally when exposed to exogenous $T$. Three $\mathrm{E}_{2}$ females were implanted at biweekly intervals with $2-\mathrm{mm}$ lengths of the unencased T/Silastic rope $(100 \mu \mathrm{g}$ of T) and were killed 30 days later. Two other $\mathrm{E}_{2}$ females were implanted with Silastic capsules which contained $\mathrm{T}$. These were fabricated by filling 3-mm lengths of Silastic tubing (Dow-Corning) of 0.047 inch, inner diameter, with crystalline $\mathrm{T}$ and then sealing their ends with RTV 738 Silastic. Survival time was 45 days after implantation. The songs developed by these $\mathrm{E}_{2}$ females and gross effects on the volume of nuclei within their song systems are described in a related paper (Gurney, 1981).

\section{Results}

Neuronal constituents of RA. In male Golgi-rapid material, the border of RA was sharply demarcated from adjacent archistriatal tissue both by the basketwork of afferent fibers which cascaded ventrally through the neostriatum and were interwoven within RA, as well as by the tendency of this dense fiber plexus to pick up background silver and thus stand out against the paler background staining of the archistriatum. In Golgi-Cox material, RA could be located in alternate sections which had been counterstained with cresyl violet. In either Golgi-Cox or Golgi-rapid material, two qualitatively different types of neurons could be distinguished in the male RA on the basis of their dendritic morphology. One type of neuron possessed dendrites which were heavily encrusted with spines (hereafter referred to as spinous neurons), while the other type of neuron had smooth, aspinous dendrites (aspinous RA neurons) (Fig. 2). In Golgi-rapid material, the dendritic spines of the former were approximately $1 \mu \mathrm{m}$ long and consisted of a slender stalk which was surmounted by a ball of $0.25 \mu$ m diameter (Fig. 3). Both spinous and aspinous RA neurons supported fairly symmetrical dendritic trees unless they were located along the periphery of RA, in which case, their dendrites arborized inwardly and remained within the border of RA (Fig. 4). Roughly equal numbers of spinous and aspinous neurons were impregnated by Golgi-rapid: from five male brains, 22 spinous and 18 aspinous neurons were obtained. The somata of both types of neurons varied from round to ovoid. For spinous RA neurons, their maximum somal diameter averaged $18 \mu \mathrm{m}( \pm 1.8$ $\mu \mathrm{m}, \mathrm{SD})$, and for aspinous neurons, it averaged $15.4 \mu \mathrm{m}$ $( \pm 1.8 \mu \mathrm{m})$. In Golgi-rapid material, several examples of each type of neuron were observed to have axons that

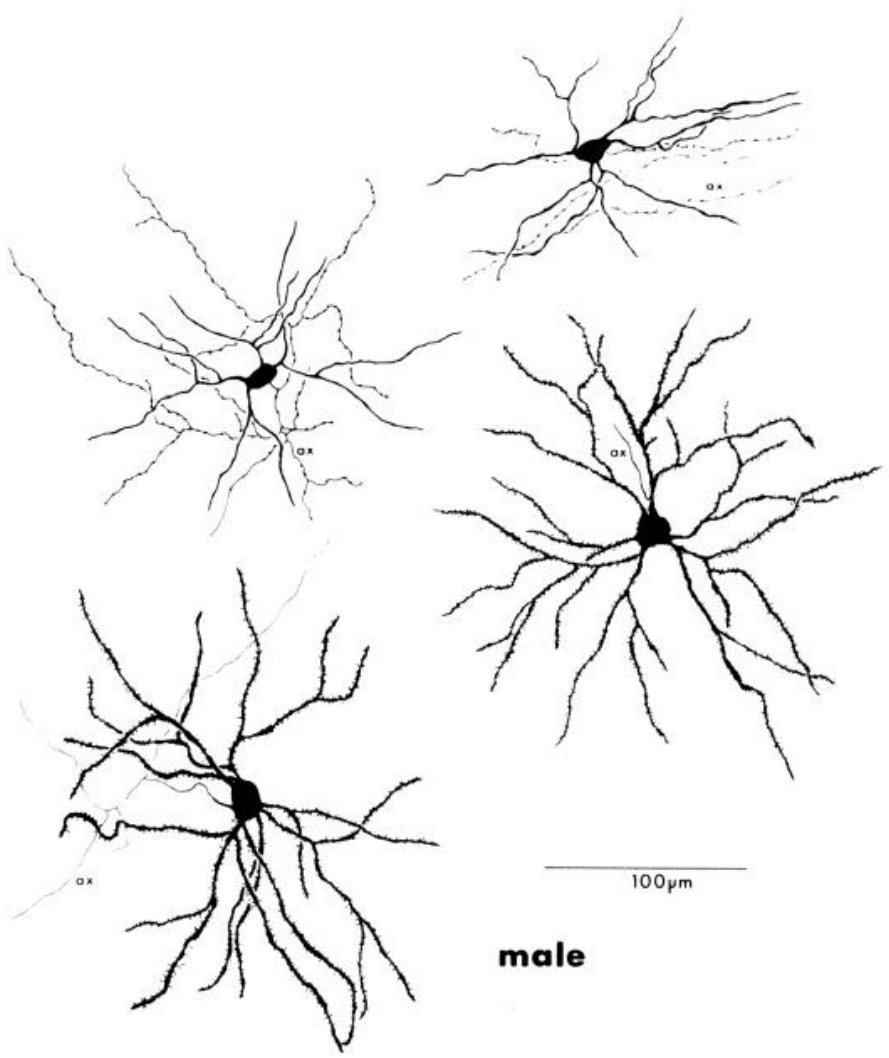

Figure 2. Light microscopic drawings which illustrate examples of Golgi-rapid-impregnated RA neurons observed in the male. Two qualitatively different classes of neurons were distinguished on the basis of whether their dendrites were spinous or aspinous. $a x$, axon. 

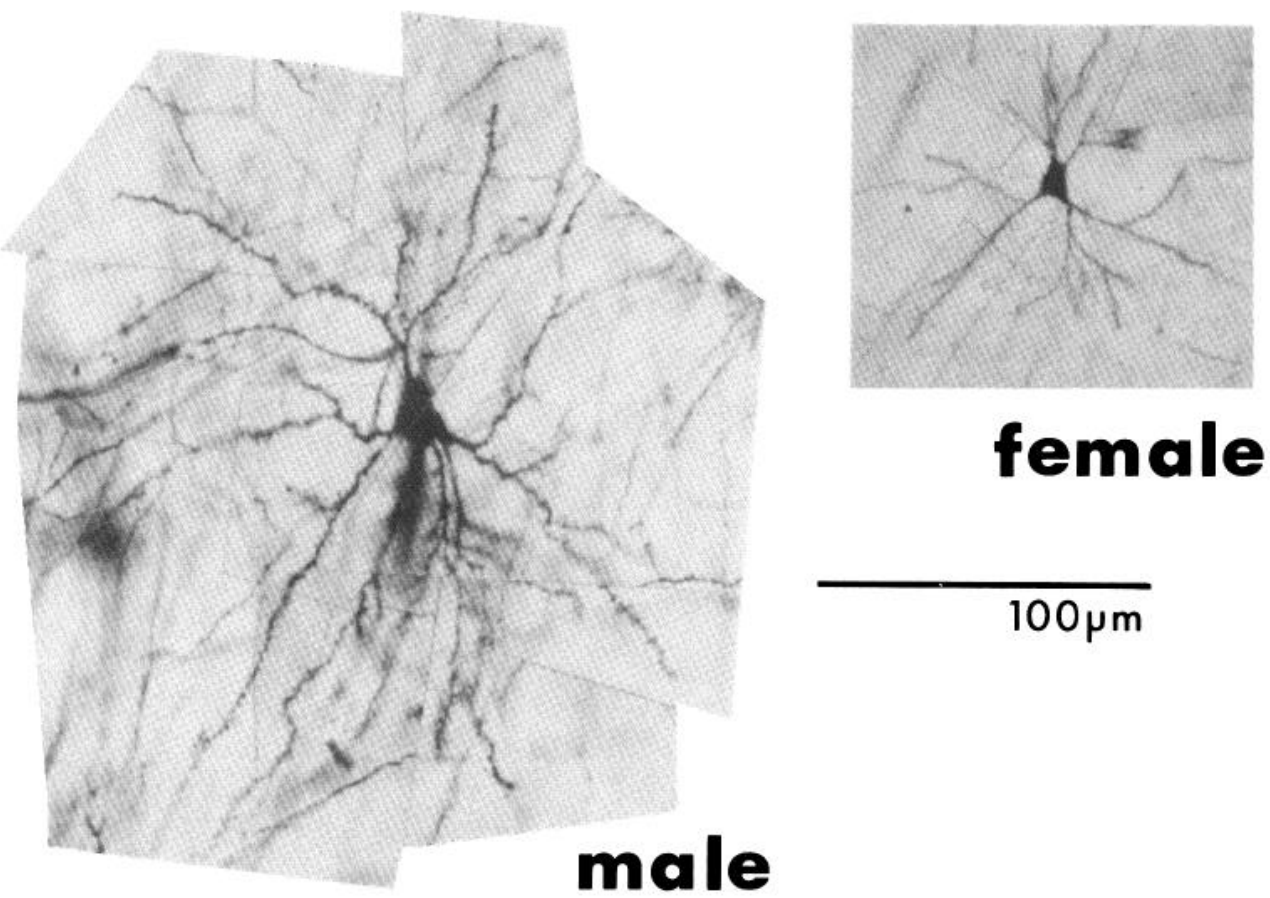

$100 \mu \mathrm{m}$

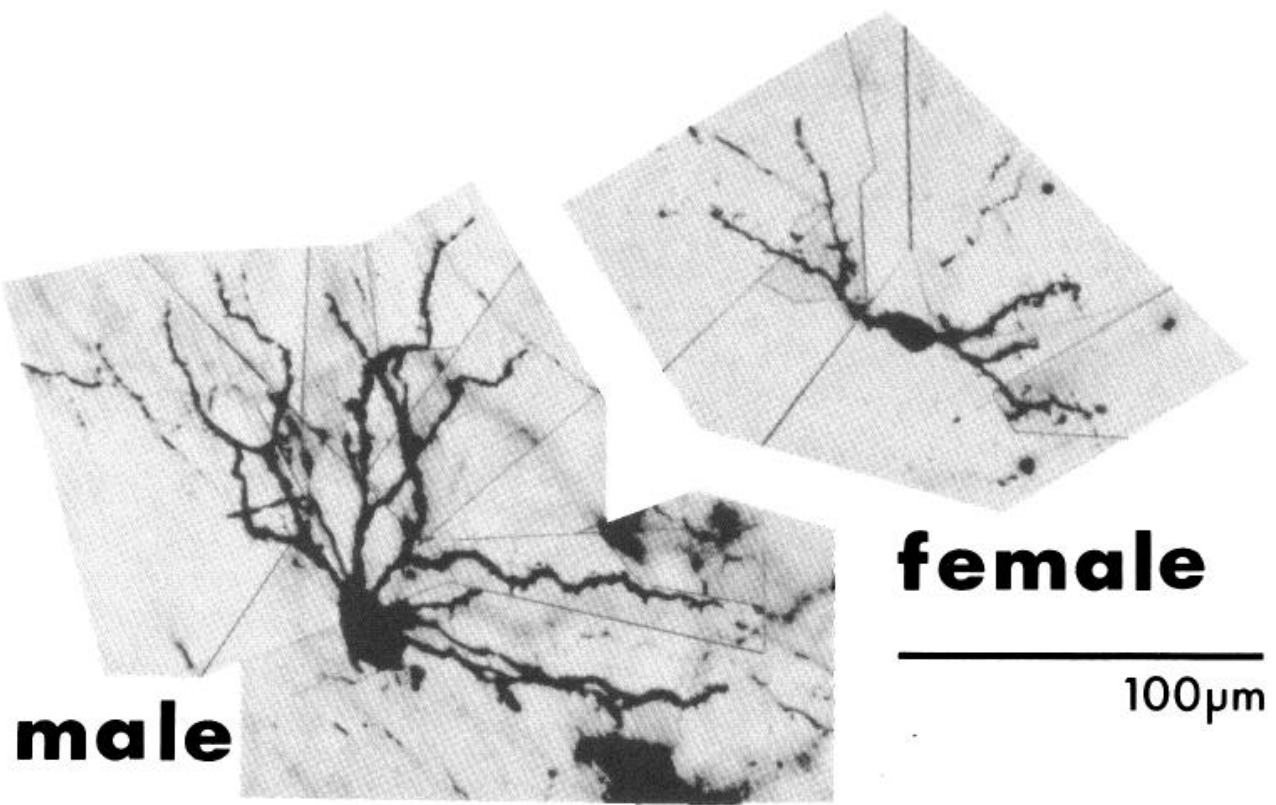

Figure 3. (upper). Comparison of Golgi-Cox-impregnated spinous RA neurons in normal adult males and females. Each of these neurons was located within the interior of RA. Note the qualitative similarity of the two neurons, though they differ in size.

Figure 4. (lower). Examples of spinous RA neurons which were located at the edge of RA. In both sexes, the dendritic arborization of spinous RA neurons remained strictly within the borders of RA.

exited RA; this suggests that both types are projection neurons. The axons of the spinous neurons gave rise to a small number of collaterals which had a smooth appearance and were of a fine caliber, $0.5 \mu \mathrm{m}$ in diameter. In contrast, the axons of aspinous neurons gave off many collaterals which branched profusely. These had a beaded appearance due to varicosities which were regularly spaced at 3 - to $5-\mu \mathrm{m}$ intervals along their length (Fig. 5). The collaterals of aspinous neurons had a fine caliber of approximately 0.1 to $0.2 \mu \mathrm{m}$ and swelled to a diameter of $0.5 \mu \mathrm{m}$ at a varicosity. The presence or absence of dendritic spines is a dichotomous classification; however, there were no obvious qualitative or quantitative differences between spinous RA neurons nor among the aspinous neurons by which to further fractionate the two categories.

The comparison of male and female Golgi material was limited to that impregnated by Golgi-Cox, as the fiber 
TABLE II

Kruskal-Wallis one-way analysis of variance by ranks of various quantitative parameters which describe the dendritic field of spinous RA neurons in male and female Golgi-Cox material

\begin{tabular}{|c|c|c|c|c|c|c|c|c|c|c|c|c|c|c|}
\hline & \multicolumn{4}{|c|}{ Males } & \multirow{2}{*}{$\begin{array}{l}\text { Aver- } \\
\text { age }\end{array}$} & \multicolumn{6}{|c|}{ Females } & \multirow{2}{*}{$\begin{array}{l}\text { Aver- } \\
\text { age }\end{array}$} & \multirow{2}{*}{$H^{a}$} & \multirow{2}{*}{$p^{b}$} \\
\hline & M1 & M2 & M3 & M4 & & $\mathrm{F} 1$ & F2 & F3 & F4 & F5 & F6 & & & \\
\hline$l_{s}(\mu \mathrm{m})^{c}$ & $23.5^{d}$ & 22.5 & 21.0 & 25.0 & 23.1 & 12.0 & 11.0 & 11.8 & 11.7 & 12.0 & 12.0 & 11.8 & 40.5 & $<0.0001$ \\
\hline$V_{d}\left(10^{6} \mu \mathrm{m}^{3}\right)$ & 10.4 & 6.0 & 10.2 & 10.6 & 9.2 & 2.2 & 1.8 & 1.9 & 2.2 & 1.4 & 1.0 & 1.7 & 44.7 & $<0.0001$ \\
\hline$I$ & 6.8 & 6.2 & 6.4 & 7.1 & 6.9 & 3.3 & 3.5 & 4.4 & 3.3 & 3.5 & 4.3 & 3.8 & 39.6 & $<0.0001$ \\
\hline$B$ & 24.1 & 20.8 & 32.0 & 33.1 & 27.5 & 16.0 & 15.0 & 13.2 & 13.3 & 12.5 & 9.7 & 13.3 & 47.3 & $<0.0001$ \\
\hline$B / I$ & 3.7 & 3.4 & 4.8 & 4.7 & 4.0 & 4.0 & 3.7 & 3.0 & 4.0 & 3.7 & 2.3 & 3.4 & 14.0 & 0.12 \\
\hline
\end{tabular}

${ }^{a}$ Statistics calculated in the Kruskal-Wallis test.

${ }^{b}$ Probability that $H \geq \chi^{2}$.

c The abbreviations used are: $l_{s}$, maximum somal diameter; $V_{d}$, volume of dendritic field; $I$, number of primary dendritic arms; $B$, number of branch segments.

${ }^{d}$ The average value of each parameter for the sample of neurons drawn from each brain is tabulated.

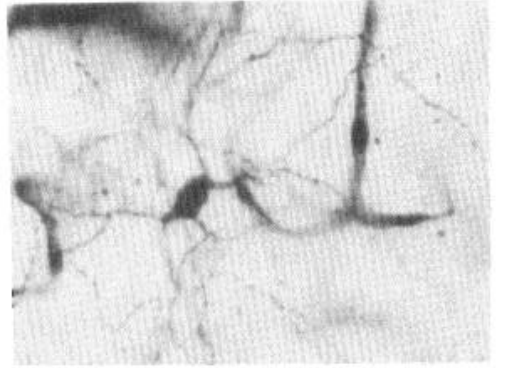

male

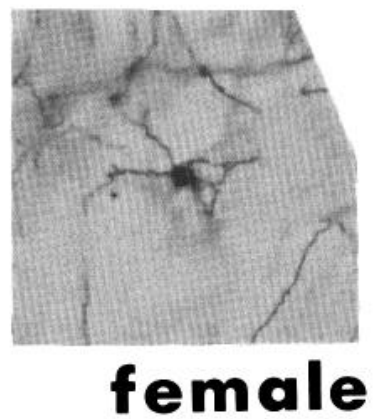

$100 \mu \mathrm{m}$

Figure 5. Comparison of aspinous RA neurons in males and females. The example of a male aspinous neuron was impregnated by Golgi-rapid, and the example from a female was impregnated by Golgi-Cox.

plexus of the female RA could not be discerned in Golgirapid material. Examples of both spinous and aspinous RA neurons were observed in female Golgi-Cox material (Figs. 3 to 5), though both types of neurons were remarkably smaller in size. Female spinous neurons qualitatively resembled those of the male: in both sexes, spinous neurons supported fairly symmetrical, dichotomously branching dendritic trees, though those of the female had a simpler structure (Fig. 3). In males, spine density usually averaged 1 spine $/ \mu \mathrm{m}$ of dendrite, while in females, the density was 1 spine $/ 3 \mu \mathrm{m}$ of dendrite. However, this sex difference should be interpreted with caution since the spines of male and female RA neurons were poorly preserved in the Golgi-Cox material and possessed an irregular shape. When located along the periphery of RA, female spinous neurons also supported dendritic trees which arborized inwardly and remained within the border of RA (Fig. 4). Aspinous RA neurons were also qualitatively similar between males and females, though once again, those of the female were considerably smaller (Fig. 5). Golgi-Cox impregnated relatively few aspinous neurons in either males or females; therefore, quantitative comparison was limited to the spinous RA neurons.

From the Golgi-Cox material, 32 well impregnated spinous neurons were selected from four male brains, and 23 neurons were selected from six female brains. All of these birds were sexually mature and in breeding condition at the time that they were killed. Two major sources of artifact were encountered in this material. First, a large number of dendritic segments were cut by the knife during sectioning, and their distal, severed fragments usually failed to impregnate with this variant of the Golgi-Cox. This introduced a bias against the male spinous neurons since their dendritic field diameter was considerably larger than the section thickness $(260-\mu \mathrm{m}$ diameter versus $120-\mu$ m-thick sections), while the dendritic field diameter of female spinous neurons $(140 \mu \mathrm{m})$ was on the order of the section thickness. The majority of the neurons selected for analysis had somata lying near the center of the section. Thus, counts of the number of branch segments were fairly accurate since most branching occurred within $50 \mu \mathrm{m}$ from the soma for male neurons and within $30 \mu \mathrm{m}$ for female neurons. The second major source of artifact was the quality of the impregnation. Poorly impregnated neurons characteristically possessed bloated somata and swollen dendrites whose distal lengths deteriorated into vesiculated fragments. Less obvious was the degree to which a neuron's fine, distal dendritic segments were impregnated. The magnitude of this artifact could not be determined but, at least in the male, was independent of the Golgi technique used since either Golgi-Cox or Golgi-rapid seemed to impregnate spinous neurons equally well. Despite these potential sources of artifact, the quantitative differences between male and female spinous RA neurons were extremely robust. Somal diameter, dendritic field volume, number of primary dendritic arms, and total number of branch segments all favored the male by a factor of 2 , and these differences were all statistically significant (Table II). Figure 6 presents Sholl plots of dendritic density as a function of distance from the soma for the male and female spinous RA neurons. The two curves have a very similar shape, though both peak dendritic density and the radial extent of the dendritic arborization are sexually dimorphic. Spinous neurons in the female supported only $3.8( \pm 0.7$, SD) primary dendritic arms as compared to $6.9( \pm 1.6, \mathrm{SD})$ in the male and significantly fewer branch segments as well, $13( \pm 3, \mathrm{SD})$ as compared to $26( \pm 10, \mathrm{SD})$. A measure of the frequency with which the dendrites of a neuron branch is the quotient of a neuron's total number of branch segments divided by its number of primary dendritic arms. The ratio of branch 


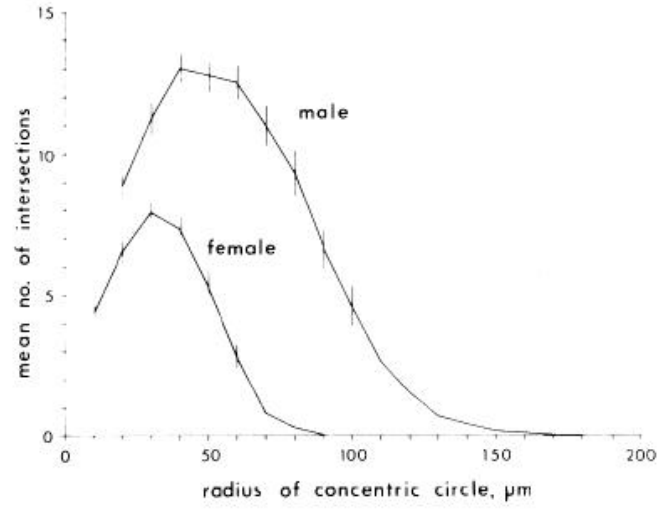

Figure 6. Sholl analysis of spinous RA neurons which compares the extent of the dendritic arborization in males and females. Neurons located within the interior of RA were selected for this analysis. Error bars indicate \pm SEM.

segments/arm for spinous neurons in the female was 3.4 $( \pm 0.9, \mathrm{SD})$ and for the male was $4.0( \pm 1.4, \mathrm{SD})$; however, this difference was not statistically significant (Table II). Thus, the frequency of branching within the dendritic field of spinous RA neurons was not sexually dimorphic yet, since female spinous RA neurons supported fewer dendritic arms, this had as its consequence an arborization which also contained fewer branch segments. Visual inspection of the neurons in Figures 3 and 4 and the Sholl plots in Figure 6 also seems to indicate that male spinous neurons support a greater length of dendrite as well.

Connectivity of RA in males and females. In view of the striking quantitative sex differences in the neuronal constituents of RA, it seemed desirable to determine whether the pattern of efferent projections from and afferent projections to RA were qualitatively similar between males and females. This pattern of connections has been previously described in the canary (Nottebohm et al., 1976; Nottebohm and Kelley, 1978). To determine the efferent projections of RA, stereotaxic injections of $\left[{ }^{3} \mathrm{H}\right]$ leucine which included RA were placed bilaterally in the archistriatum (A) of two males and two females. The efferent projections of RA are strictly ipsilateral in the canary (Nottebohm et al., 1976), and this was confirmed in the zebra finch by placing a unilateral injection of $\left[{ }^{3} \mathrm{H}\right]$ leucine in the RA of a third male. From all of the injection sites in the males (Fig. 7), anterograde transport of tritium-labeled material led to a heavy accumulation of label over a region within the nucleus intercollicularis (ICO) and over the posterior two-thirds of the hypoglossal nucleus (nXII) (Fig. 8). A sparse accumulation of silver grains was also observed over the rest of ICO and through the lateral reticular formation (LRF), although this could represent either fibers of passage or terminal labeling. The area of heaviest labeling within ICO was cytoarchitectonically distinct from ICO proper. It was a large celled area which was surrounded by a thin, acellular lamina, and it lay just dorsomedial to the nucleus mesencephalicus lateralis, pars dorsalis (MLd), beneath the anterior limb of the tectal ventricle. In view of its discrete nature, I will refer to this structure as the dorsomedial intercollicular nucleus (DM). The efferent projections of RA were qualitatively similar in the female. Injections B280-12, B280-8, O100-4, and 0100-10 all in-
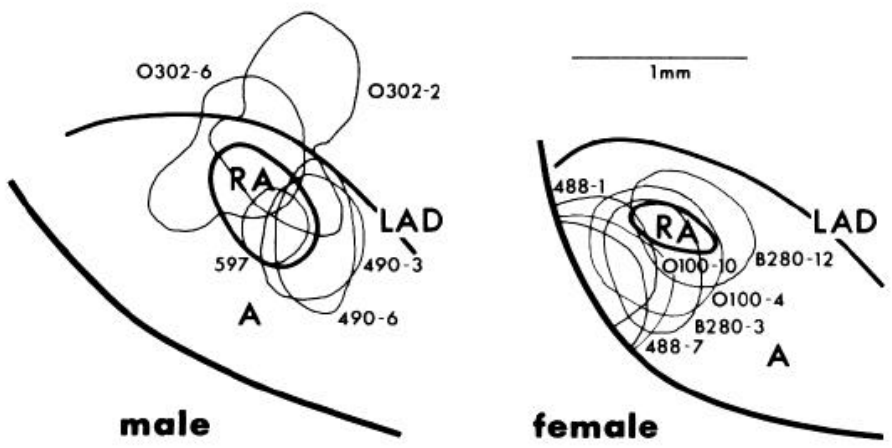

Figure 7. The injection sites of $\left[{ }^{3} \mathrm{H}\right]$ leucine into RA. One male was injected unilaterally (597) and two males received bilateral injections of RA (O302 and 490). Transport of ${ }^{3} \mathrm{H}$ labeled material from the unilateral injection in male 597 was strictly ipsilateral. From all five injections, transport of labeled material to DM, ICO, dorsal SpM, DTh, LRF, and nXIIts was observed. Three females received bilateral injections of $\left[{ }^{3} \mathrm{H}\right]$ leucine. The injections of females B280 and 099 were centered on RA and the transport of ${ }^{3} \mathrm{H}$-labeled material which was observed was similar to that of the males. One female was injected deep to RA and no transport of ${ }^{3} \mathrm{H}$-labeled material to any of the above nuclei was observed.
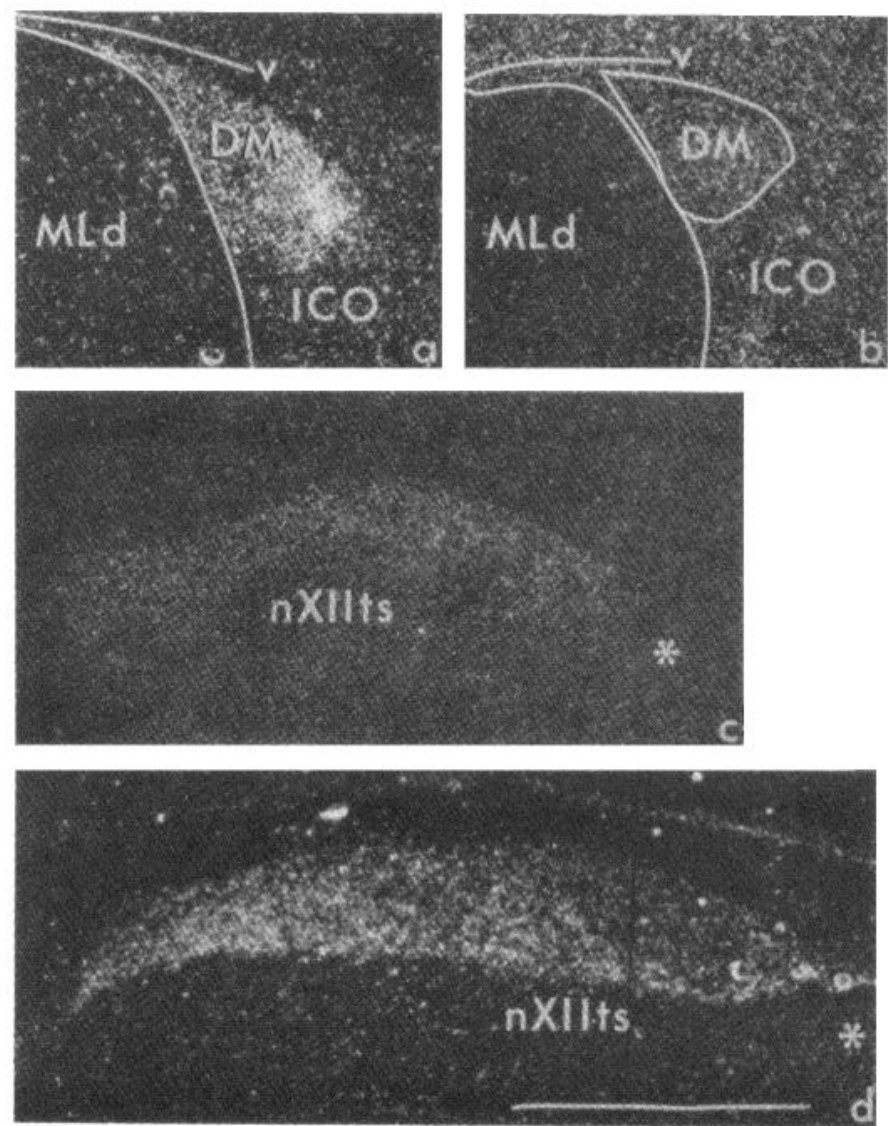

Figure 8. Dark-field autoradiographs which illustrate the terminal field of RA upon DM and nXIIts. $a$, DM of male 597. ICO is sparsely labeled and MLd is free of specific labeling. $b$, DM of female B280-12. Unlike the male, the density of labeling over DM and ICO was equivalent, while MLd is again free of specific labeling. $c$, nXIIts of female B280-3. Asterisk indicates the anterior, lingual portion of nXII. $d$, nXIIts of male O302-6; specific labeling is absent over the anterior portion of nXII. All of these photographs are of sagittal sections; anterior is to the right. The scale bar is $60 \mu \mathrm{m}$ for $a$ and $b ; 500 \mu \mathrm{m}$ for $c$ and $d$. 
cluded RA (Fig. 7) and resulted in labeling over the DM/ ICO complex and over the posterior two-thirds of nXII (Fig. 8). In the male, labeling over DM was clearly heavier than that over adjacent areas of ICO, while in the female, the density of labeling over DM and ICO was equivalent (Fig. 8).

Since all of the injections of $\left[{ }^{3} \mathrm{H}\right]$ leucine included adjacent archistriatal areas as well as RA, the neurons of origin were located by retrograde labeling with HRP. Stereotaxic injections of HRP were placed bilaterally in the DM/ICO complex of two adult males and two females. From all of these injections, retrogradely labeled neurons predominated in RA, although a few HRP-labeled neurons were also found to be scattered within archistriatal areas anterior to RA (Fig. 9). The major efferent projections of the anterior and intermediate divisions of the archistriatum in pigeons have been shown to travel in the tractus occipitomesencephalicus (OM) (Zeier and Karten, 1971). Since the injections of HRP penetrated this tract in the zebra finch, some of the labeled neurons in the anterior archistriatum (and RA as well) might have taken up HRP due to their axons having been damaged. To identify the neurons which project to nXII, unilateral injections of HRP were placed in the medullas of three males and one female (Fig. 9). Only the injections which included the posterior two-thirds of nXII resulted in retrograde labeling of neurons within RA. A projection from DM to nXII was also identified. After the injections in male 523 and female O104, many HRP-labeled neurons were clustered within DM, and a few scattered neurons were also observed in ventral ICO.

The posterior two-thirds of nXII has been reported to innervate the syrinx of canaries (Nottebohm et al., 1976) and zebra finches (Arnold et al., 1976) via the tracheosyringeal branch of the hypoglossal nerve, although the obvious cytoarchitectonic demarcation between its an-
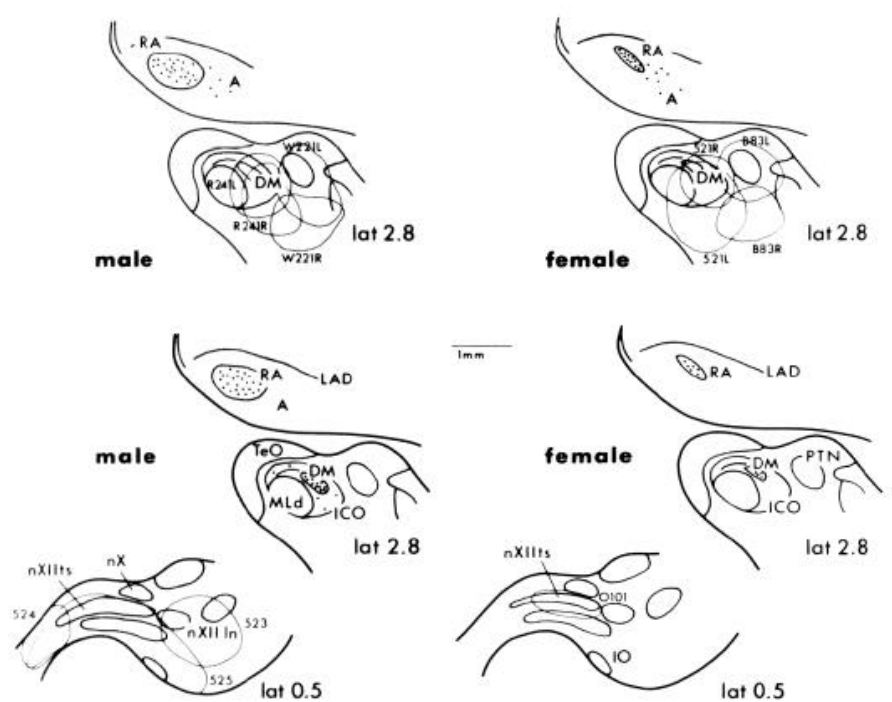

Figure 9. Charting of the distribution of HRP-labeled neurons after injection of the enzyme into DM/ICO (top) or nXIIts ( bottom). At top left, the distribution of labeled neurons (dots) after injection R241L into DM/ICO is charted for the male. At top right, the distribution of labeled cells after injection $521 \mathrm{R}$ into DM/ICO is charted for the female. Of the HRP injections into the medulla of males, only injection 525 resulted in retrograde labeling of neurons in DM/ICO and RA.

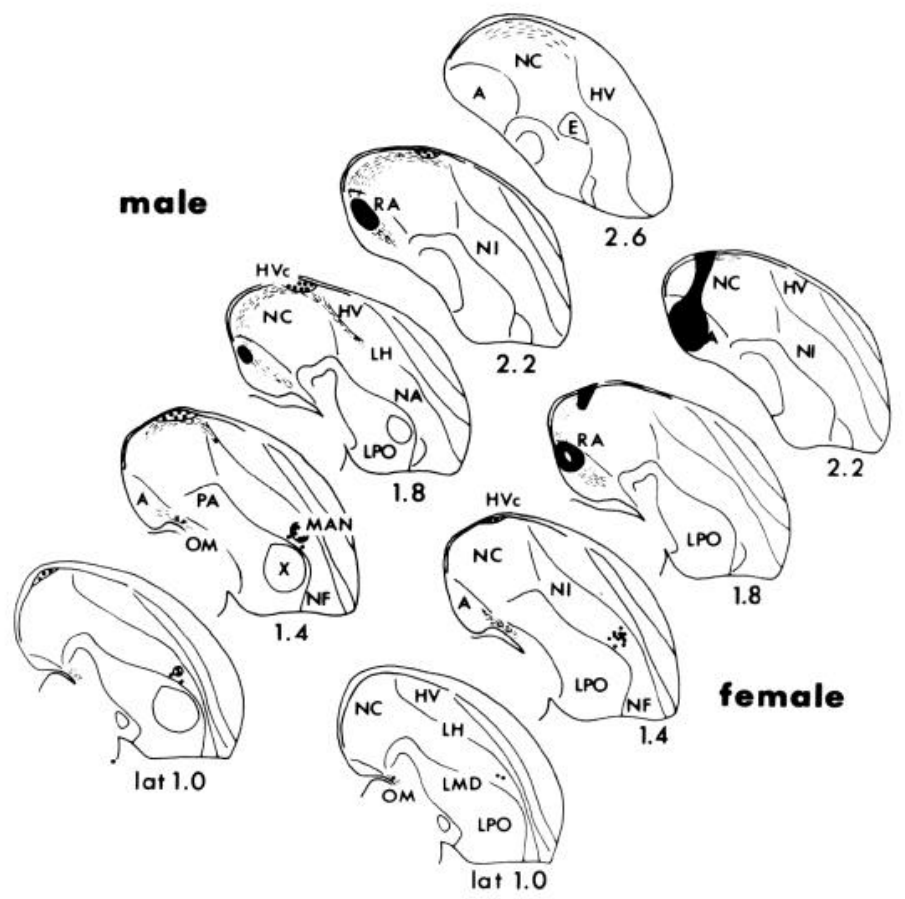

Figure 10. The distribution of HRP-labeled neurons after injection of the enzyme into RA. In both sexes, scattered labeled cells (dots) were observed throughout the extent of HVc. In the male, labeled neurons also were clustered within MAN. In the female, MAN is not well demarcated from adjacent neostriatal tissue, but a similar clustering of labeled neurons, ventral to $\mathrm{LH}$, was observed.

terior and posterior divisions, apparent in sagittal sections (Fig. 14), had not been remarked upon in the past. To verify that the axons of motor neurons within the posterior division of nXII did travel down the nervi tracheosyringealis, this nerve was severed on the right side of four adult males. After survival times of 7 or 9 days, they were killed and the location of chromatolytic neurons was determined. All of the large cells within the posterior division of nXII possessed swollen somata, very densely staining Nissl substance, and eccentric nuclei, all classical signs of chromatolysis (Fig. 14). No chromatolytic neurons were observed within the anterior division of nXII. Thus, the projection from RA terminates precisely upon the motor neurons which innervate the syrinx.

In the canary, RA has been reported to receive two sets of afferent projections, one from HVc (Nottebohm et al., 1976) and a second from the magnocellular nucleus of the anterior neostriatum (MAN) (Nottebohm and Kelley, 1978). A similar pattern of afferents was observed in both male and female zebra finches. Two males and three females received unilateral injections of HRP in RA. A lateral approach to RA at a slant $30^{\circ}$ from the vertical was used to avoid damaging $\mathrm{HV} c$ or disrupting non-song system afferents which run within the tractus archistriatalis dorsalis. After RA injections in either males or females, one group of HRP-labeled neurons was scattered throughout the HVc of both sexes, and a second group of labeled neurons was observed in the anterior neostriatum (Fig. 10). In the male, labeled neurons were observed in MAN and were the large-bodied neurons characteristic of the nucleus. In adult females, the cy- 
toarchitecture of MAN was not well demarcated from surrounding areas in the anterior neostriatum, though the majority of neurons which labeled with HRP from RA were clustered in a compact group immediately ventral to the lamina hyperstriatica $(\mathrm{LH})$. This position is homologous to that of MAN in the male.

Cellular effects of $E_{2}, D H T$, and T when administered at hatching. When administered to male chicks at hatching, neither $\mathbf{E}_{2}$ nor DHT influence the development of a stereotyped song nor the development of the sexual dimorphism in the song system, whereas administration of $\mathrm{E}_{2}$ to female chicks masculinizes both the female's behavioral capacity for song and the cytoarchitecture of the telencephalic song nuclei (RA, HVc, MAN, and X) (Gurney and Konishi, 1980; Gurney, 1981). Administration of DHT does not masculinize the female's behavioral capacity for song. The following analysis focuses on the female and will describe the cellular consequences in RA of exposure to $\mathrm{E}_{2}$ or DHT at hatching. Exposure to $\mathrm{E}_{2}$ was found to influence parameters of neuronal size predominantly, and DHT was found to influence neuronal number.

The experimental material described above was used to develop cytological criteria for distinguishing the projection neurons of RA from non-neuronal cells. In frozen sections of the male RA which were stained with cresyl violet, three types of cells were observed. The first cell type, which provided the cytoarchitecture of RA its diagnostic feature, had a large, ovoid soma and possessed a large, round nucleus whose watery nucleoplasm contained one distinct nucleolus. Its nucleus was ringed by a distinct nuclear membrane, and its cytoplasm was filled with abundant Nissl substance of pronounced basophilia (Fig. 11). In all cases examined, injection of HRP into $\mathrm{DM} / \mathrm{ICO}$ or nXIIts retrogradely labeled this type of cell, and in no cases did HRP label any examples of the other two types of cells. In the female RA, no examples of this sort of large neuron were observed. Instead, in all cases examined, retrograde transport of HRP from DM/ICO
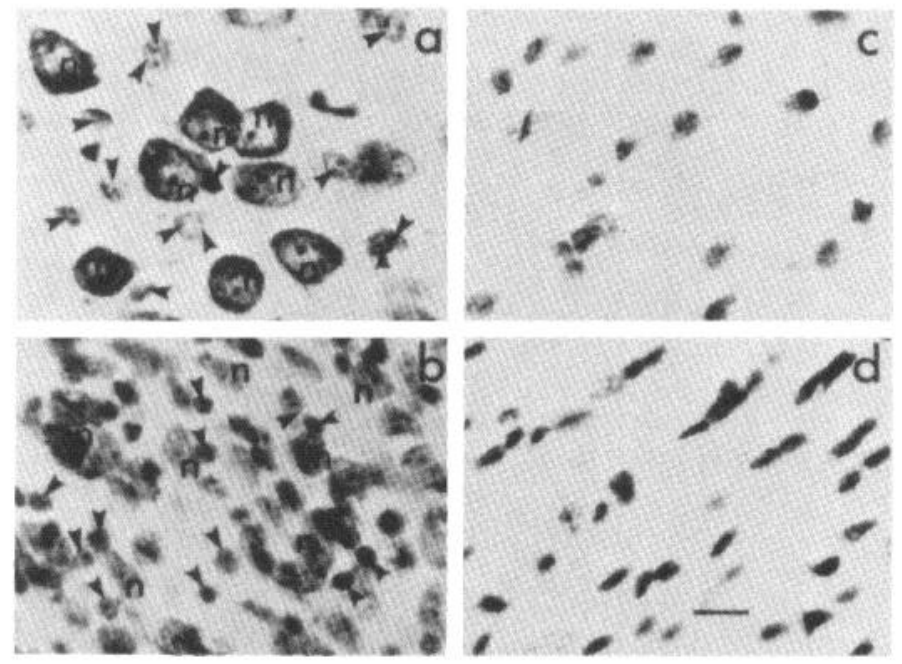

Figure 11. Cytology of neurons $(n)$ and non-neuronal cells (arrowheads) in the zebra finch brain. $a$, Male RA; $b$, female $\mathrm{RA} ; c$, occipitomesencephalic tract in a male; $d$, optic tract in a female. These 10- $\mu$ m-thick, paraffin-embedded sections were stained with thionin. Scale bar equals $10 \mu \mathrm{m}$. or nXIIts labeled a small-bodied cell. Its soma was more elongate than in the male; its nucleus was stained lightly, contained one distinct nucleolus, and was ringed by a distinct nuclear membrane. As a consequence of its elongate soma, the cytoplasm of female RA neurons often looked as if it capped the nucleus at opposite ends. Since the Golgi analysis described above delimited only two types of RA neurons in either males or females, both of which seemed to be projection neurons, these cytological criteria should be sufficient to identify all of the neurons in RA. In both males and females, the other cell types in RA possessed somata approximately $5 \mu \mathrm{m}$ in diameter. One type had a compressed elongate soma, lacked a distinct nucleus, and had an overall pronounced basophilia which was granular in texture. The other type of cell was ovoid and had a very lightly staining soma with little cytoplasm. Its nuclear envelope was indistinct and its watery nucleoplasm contained from 1 to 5 nucleoli as well as many small, densely staining clumps of chromatin. Both of these cell types were also observed in the zebra finch tractus occipitomesencephalicus and within the optic tract (Fig. 11). They are presumed to be nonneuronal cells, and their morphology is similar to that attributed to oligodendrocytes and astrocytes, respectively, by Ling et al. (1973).

The size of a neuron's soma provides a convenient and sensitive assay of its sexually differentiated state. Within each sex, the distribution of somal diameters for RA neurons was unimodal, and the size distributions characteristic of males did not overlap with those characteristic of females (Fig. 12). In males, the somal diameters of RA neurons averaged $17.8 \mu \mathrm{m}$ ( 16.3 to $18.8 \mu \mathrm{m}$ ), while in females, somal diameter averaged only $8.2 \mu \mathrm{m}(7.2$ to $8.7 \mu \mathrm{m})$. Exposure to $\mathrm{E}_{2}$ at hatching masculinized the cytoarchitecture of RA (Fig. 13). The distribution of somal diameters for RA neurons in adult $\mathrm{E}_{2}$ females remained unimodal but was now shifted to an average diameter of $15.9 \mu \mathrm{m}$ (14.6 to $17.0 \mu \mathrm{m}$ ) (Table III; MannWhitney $U$ test, $p=0.005$ ). If the RA of $\mathrm{E}_{2}$ females contained neurons which had not responded to $E_{2}$, the distribution of somal diameters should have become bimodal with one peak near $15.9 \mu \mathrm{m}$ (of neurons masculinized by $\mathrm{E}_{2}$ ) and a second peak near $8.2 \mu \mathrm{m}$ (corresponding to neurons which did not respond to $\mathrm{E}_{2}$ and remained female-like in size) (see Fig. 12). Since the size distribution was unimodal, at least $95 \%$ (based on a sample size of 100 to $150 \mathrm{RA}$ neurons) of the neurons within the RA of adult $\mathrm{E}_{2}$ females were masculinized with respect to somal size. Exposure to DHT at hatching exerted a small influence on the somal diameter of RA neurons. In DHT females, somal diameter averaged $9.3 \mu \mathrm{m}$ (9.0 to $10.2 \mu \mathrm{m})$ which was significantly different from the somal diameter of RA neurons in unimplanted females (Mann-Whitney $U$ test, $p=0.002$ ).

The number of neurons in RA was also sexually dimorphic. In normal males, $16,400(16,000$ to 16,900$)$ neurons were observed, while only half of this number of neurons, $6,950(6,000$ to 7,600$)$, were present in the RA of normal females. One source of error in counts of neuronal number might have been the misclassification of neurons and non-neuronal cells. However, such errors could not account for the observed sex difference since the ob- 


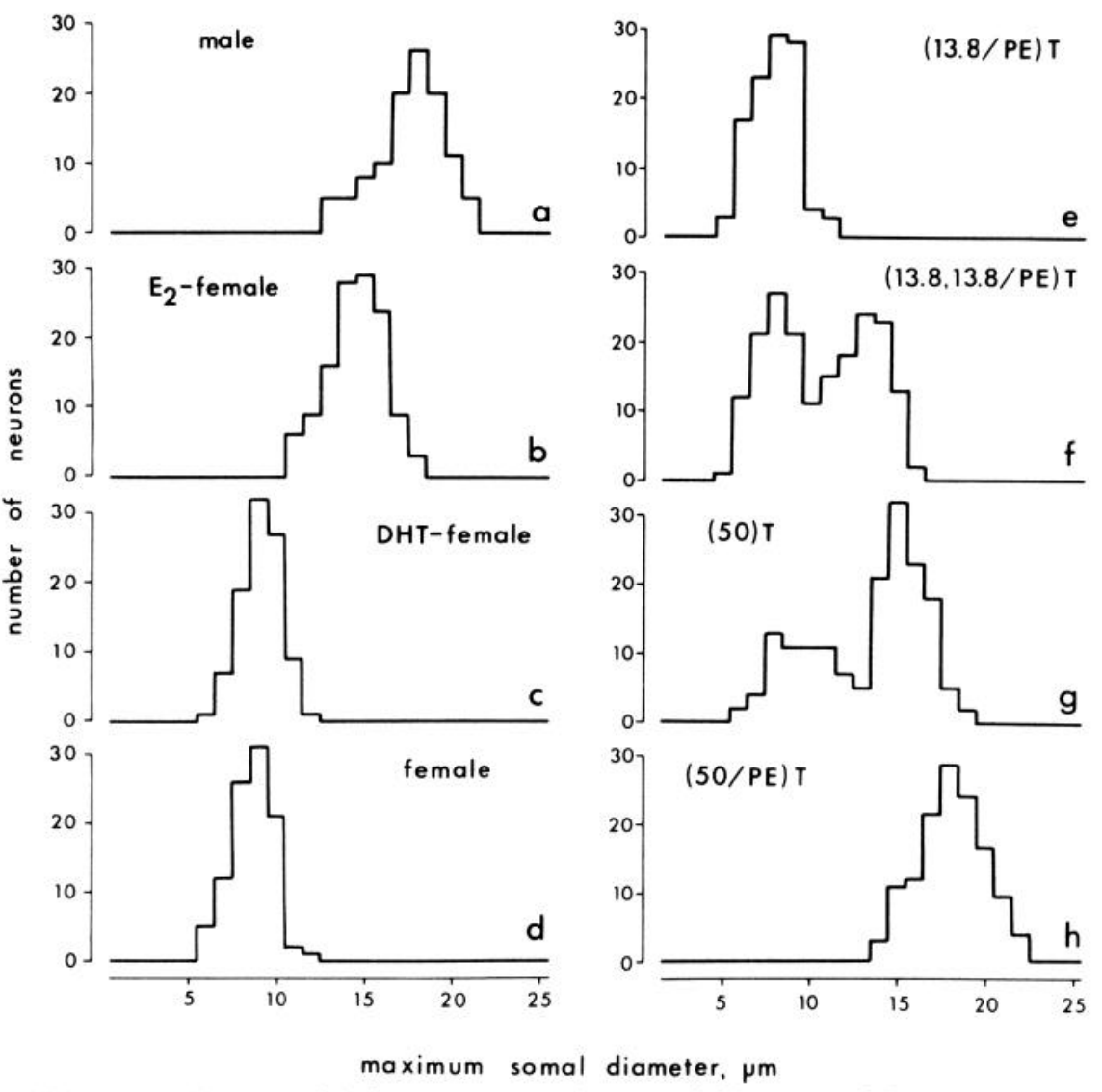

Figure 12. Hormonal influences upon the somal diameter of RA neurons. $a$, Normal male; $b, \mathrm{E}_{2}$ female; $c$, DHT female; $d$, normal female; $e$, (13.8/PE)T female; $f,(13.8,13.8 / \mathrm{PE}) \mathrm{T}$ female; $g$, (50)T female; $h$, $(50 / \mathrm{PE}) \mathrm{T}$ female.

TABLE III

The values tabulated are averages (low-high)

Cellular parameters of $R A$ in experimental and control groups

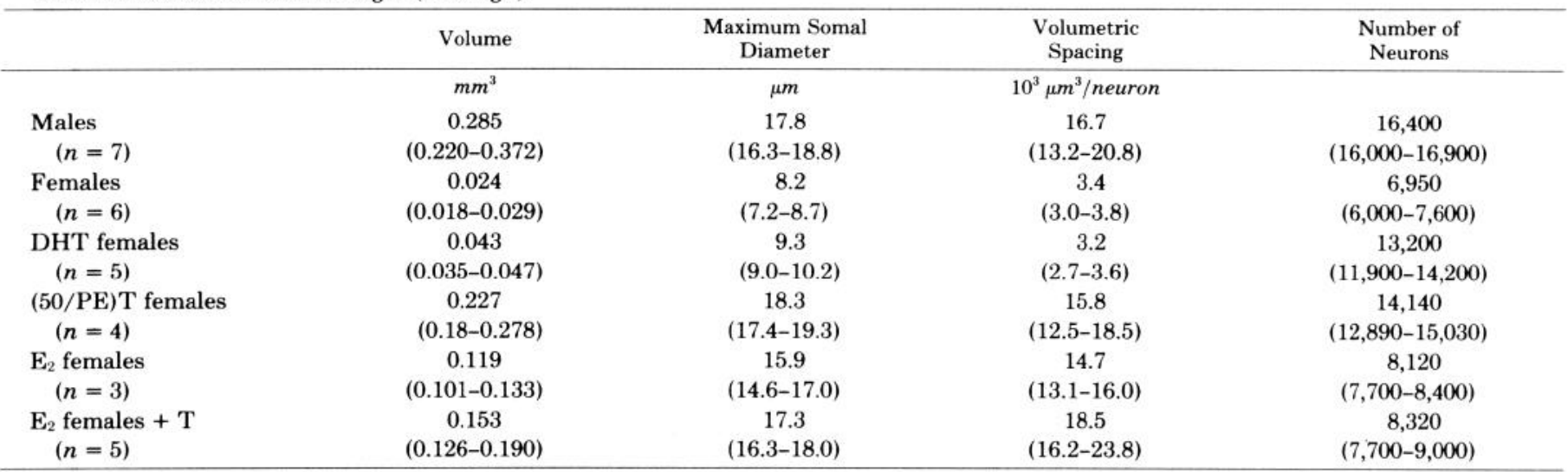

served ratio of neurons/non-neuronal cells was $0.32(0.22$ to 0.42$)$ in the males and $0.72(0.59$ to 0.85$)$ in the females. This gives an average of 67,650 cells in the male RA as compared to an average of 16,600 cells in the female RA. Exposure to DHT at hatching exerted a large influence on the number of neurons in RA, though there was little effect on its cytoarchitecture (Fig. 13). RA remained filled with small, densely packed cells, though its volume was expanded 1.8-fold. The expansion in its volume was due to an increase in neuronal number from an average of 6,950 neurons in unimplanted females to $13,200(11,900$ to 14,200 ) neurons in DHT females (Table III; MannWhitney $U$ test, $p=0.002$ ). The number of RA neurons in DHT females was still significantly less than the number in normal males $(p=0.001)$. Exposure to $\mathrm{E}_{2}$ at hatching also exerted a slight influence on the number of RA neurons in females. Neuronal number increased by $20 \%$ from 6,950 to $8,120(7,700$ to 8,400$)(p=0.001)$.

Since Callard et al. (1978) have shown that telencephalic tissue from Gallus domesticus has the capacity to aromatize $\mathrm{T}$ to $\mathrm{E}_{2}$, it seemed reasonable to test whether administration of $\mathrm{T}$ to female chicks at hatching would 

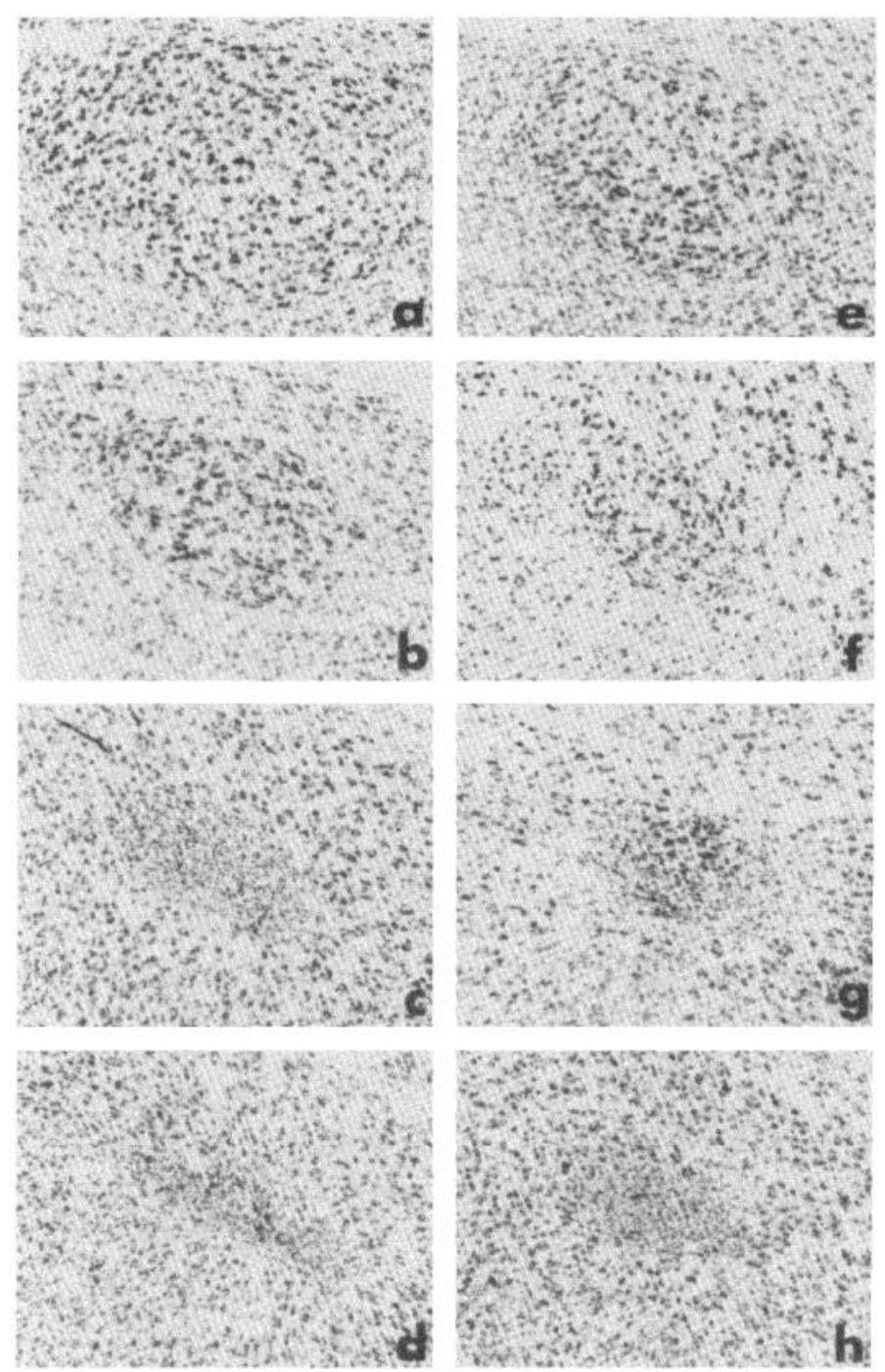

Figure 13. Hormonal influences upon the cytoarchitecture of RA. $a$, Normal male; $b, \mathrm{E}_{2}$ female; $c$, DHT female; $d$, normal female; $e,(50 / \mathrm{PE}) \mathrm{T}$ female; $f,(50) \mathrm{T}$ female; $g,(13.8,13.8 / \mathrm{PE}) \mathrm{T}$ female; $h$, (13.8/PE)T female. Sagittal sections are shown; anterior is to the right. Approximate magnification is $\times 55$.

result in the masculinization of both cytoarchitecture (via its putative aromatization to $\mathrm{E}_{2}$ ) and neuronal number (acting as T or via reduction to DHT) within RA. Two styles of $T$ implants were used: the first held the steroid in a Silastic matrix, and the second held the steroid in a Silastic matrix partially encased in PE tubing. The two types of implants differed in the half-life of their rate of $\mathrm{T}$ release; the first released $\mathrm{T}$ with a half-life of $13.0 \mathrm{hr}$ and the second with a half-life of $41.0 \mathrm{hr}$. Table I gives a description of these pellets and their schedule of implantation, and Figure 1 gives the (calculated) amount of hormone delivered per day per gm of body weight as a function of the age of the chick. Females that received the (13.8/PE) T implant at hatching showed no response in RA. Neither the number of neurons, $7,310(6,350$ to 7,500; four females), nor the average somal diameter of RA neurons, $8.5 \mu \mathrm{m}$ ( 7.5 to $8.9 \mu \mathrm{m})$, differed from unimplanted females. In contrast, the $(50 / \mathrm{PE}) \mathrm{T}$ implants masculinized both the cytoarchitecture and the number of neurons in RA. Neuronal number in $(50 / \mathrm{PE}) \mathrm{T}$ females doubled to an average of 14,140 , and their somal diameter averaged $18.4 \mu \mathrm{m}$ (Table III). In all of the (13.8/PE)T or (50/PE) T females, the distributions of somal diameter for RA neurons remained unimodal (Fig. 12). If the amount of hormone released by the (13.8/PE) T implants during the first 4 days of exposure is taken as the maximum threshold of $\mathrm{T}$ exposure which is unable to elicit the masculinization of RA, then the $(50) \mathrm{E}_{2}$ implants exceeded this threshold by 2.4 -fold and the $(50 / \mathrm{PE}) \mathrm{T}$ implants by 3.7 -fold. Although the blood levels of hormone maintained by these various implants are unknown, it would seem that they are not unreasonably above the minimum threshold dose which would be required to elicit the sexual differentiation of RA.

Unlike the complete masculinization of RA achieved with the (50/PE)T implants, either the $(13.8,13.8 / \mathrm{PE}) \mathrm{T}$ or (50) $\mathrm{T}$ implants resulted in the masculinization of only a fraction of the neurons in RA (Figs. 12 and 13). The $\mathrm{RA}$ of adult females that received either of these implants at hatching contained a mixture of large- and smallbodied neurons. The distributions of somal diameter for RA neurons in five (50)T and three $(13.8,13.8 / \mathrm{PE}) \mathrm{T}$ females were all bimodal; one peak of neurons always fell within the size range characteristic of unimplanted females $(8$ to $9 \mu \mathrm{m})$, and the second peak fell within the range characteristic of masculinized RA neurons (13 to $16 \mu \mathrm{m})$ as seen in Figure 12. The ratio of the number of small to large neurons varied from female to female, though the ratio tended to favor small neurons in (13.8, 13.8/PE) $\mathrm{T}$ females and large neurons in (50) $\mathrm{T}$ females. Masculinized, large-bodied neurons tended to occupy the interior of RA and their number decreased toward the periphery of the nucleus, while small-bodied neurons predominated in the periphery of RA. This created a heterogeneous distribution of neuronal density within the RA of these females and made estimates of neuronal number unreliable. Both the (13.8/PE)T and $(13.8,13.8$ / PE) T implants delivered the same peak dose of $\mathrm{T}$, while the latter implants maintained a slightly higher level of hormone exposure over a longer period (Fig. 1). Yet, only the $(13.8,13.8 / \mathrm{PE}) \mathrm{T}$ implants resulted in the masculinization of neurons within RA. Note that the $(50) \mathrm{T}$ and (50)DHT implants released hormone with nearly identical time courses. From both, initial release of hormone reached "pharmacological" levels and then decayed rapidly, yet large-bodied neurons were observed only within the RA of (50)T females and not in (50)DHT females. Taken with the effect of $\mathrm{E}_{2}$ at hatching, this suggests that aromatizable androgen is required for the masculinization of neuronal size within RA.

Neuronal number was not measurable in $\mathrm{HVc}$ due to the difficulty of distinguishing non-neuronal cells from an HVc neuron that projects to RA which has a small soma and scanty cytoplasm.

To determine whether the sex difference in neuronal number within RA reflects similar differences within the song nuclei which are its efferent targets, neuronal number in DM and nXIIts was also determined. No sex differences in neuronal number were observed within either of these nuclei (Table IV).

Cellular effects of T or DHT in the adult. Exposure of gonadally intact, adult females to either T or DHT, but not to $\mathrm{E}_{2}$, results in the sexual differentiation of both DM 
TABLE IV

Cellular parameters of $n X I I t s$ and DM in experimental and control groups

The values tabulated are averages (low-high).

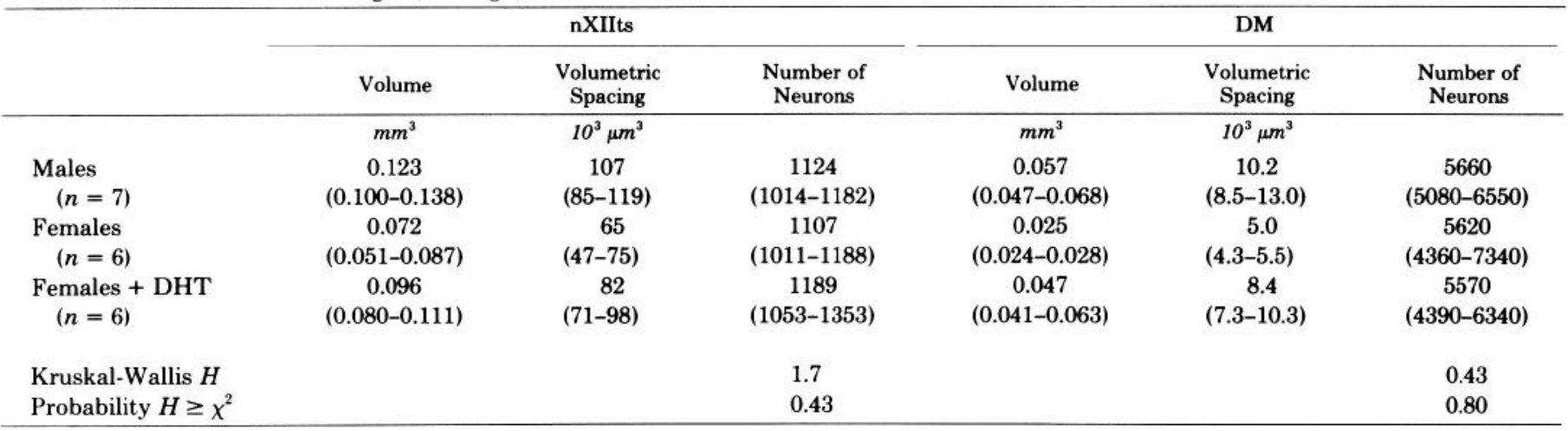

and nXIIts (Gurney and Konishi, 1980; Gurney, 1981). Six females were implanted with Silastic pellets which contained $100 \mu \mathrm{g}$ of DHT and then killed for histological examination 30 days later. The nXIIts of one such female is compared to that of a normal male and an unimplanted female in Figure 14. The increase in the volume of either nXIIts or DM elicited by exposure to exogenous DHT was mediated by an increase in neuronal spacing, not an increase in neuronal number (Table IV).

The process of sexual differentiation within the telencephalic song nuclei of the zebra finch has two phases (Gurney and Konishi, 1980; Gurney, 1981). Early exposure to $\mathrm{E}_{2}$ patterns their cytoarchitectonic masculinization and is a prerequisite for the development of androgen responsiveness (defined behaviorally and morphologically) in the adult. When adult $\mathrm{E}_{2}$ females are brought into song by exposure to T or DHT, the volumes of RA, HVc, MAN, and X all increase (Gurney and Konishi, 1980; Gurney, 1981). To determine if the number of RA neurons changed when adult $\mathrm{E}_{2}$ females were exposed to androgen, a group of $\mathrm{E}_{2}$ females were given either multiple implants of Silastic pellets which contained $100 \mu \mathrm{g}$ of $\mathrm{T}$ or $\mathrm{T}$-filled capsules which were fabricated from Silastic tubing. The song behavior of these birds and a description of the morphological response of the telencephalic song nuclei are given in a related paper (Gurney, 1981). The increase in the volume of RA was mediated by an increase in neuronal spacing, not by a change in neuronal number (Table III). In either $\mathrm{E}_{2}$ females or $\mathrm{E}_{2}$ females exposed to exogenous $\mathrm{T}$, somal diameter and neuronal spacing were not significantly different from the male, though androgen produced a significant increase in the values of these parameters when compared between the two groups of $\mathrm{E}_{2}$ females (Mann-Whitney $U$ test, $p=0.036$ ). The influence of exposure to DHT on the total volume and the spacing of neurons in DM and nXIIts of normal adult females and in RA of $E_{2}$ females was graded (Fig. 15). In contrast, early exposure to $\mathrm{E}_{2}$ produced an abrupt transition in the average spacing of RA neurons.

\section{Discussion}

The label "song system" refers to a group of interconnected brain nuclei, some of whose lesion results in a deficit in song. Our understanding of this system is by no means complete; sensory inputs (auditory? propriocep-
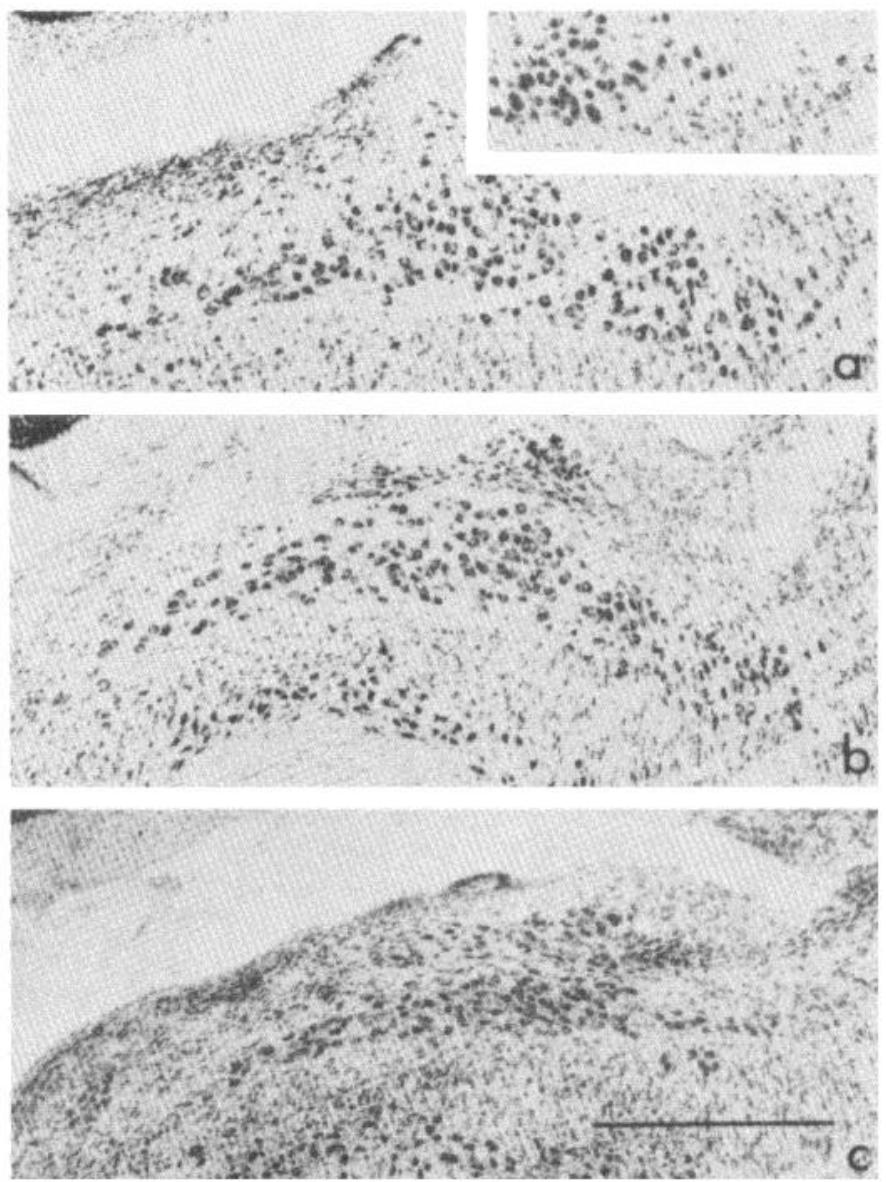

Figure 14. Influence of DHT on the cytoarchitecture of nXIIts. $a$, Normal male; inset, nXII after section of the ipsilateral nervi tracheosyringealis. Chromatolytic neurons were only observed in the posterior two-thirds of nXII. $b$, An adult female who had been implanted with a Silastic pellet which contained $100 \mu \mathrm{g}$ of DHT; $c$, normal female. Anterior is to the right. Scale bar equals $500 \mu \mathrm{m}$.

tive?) are ill defined as are possible hypothalamo-preoptic connections and the circuitry which coordinates breathing with syringeal control. At a gross level of organization, the connections between different song nuclei in males and females which were compared in this report were remarkably similar, especially in view of the 


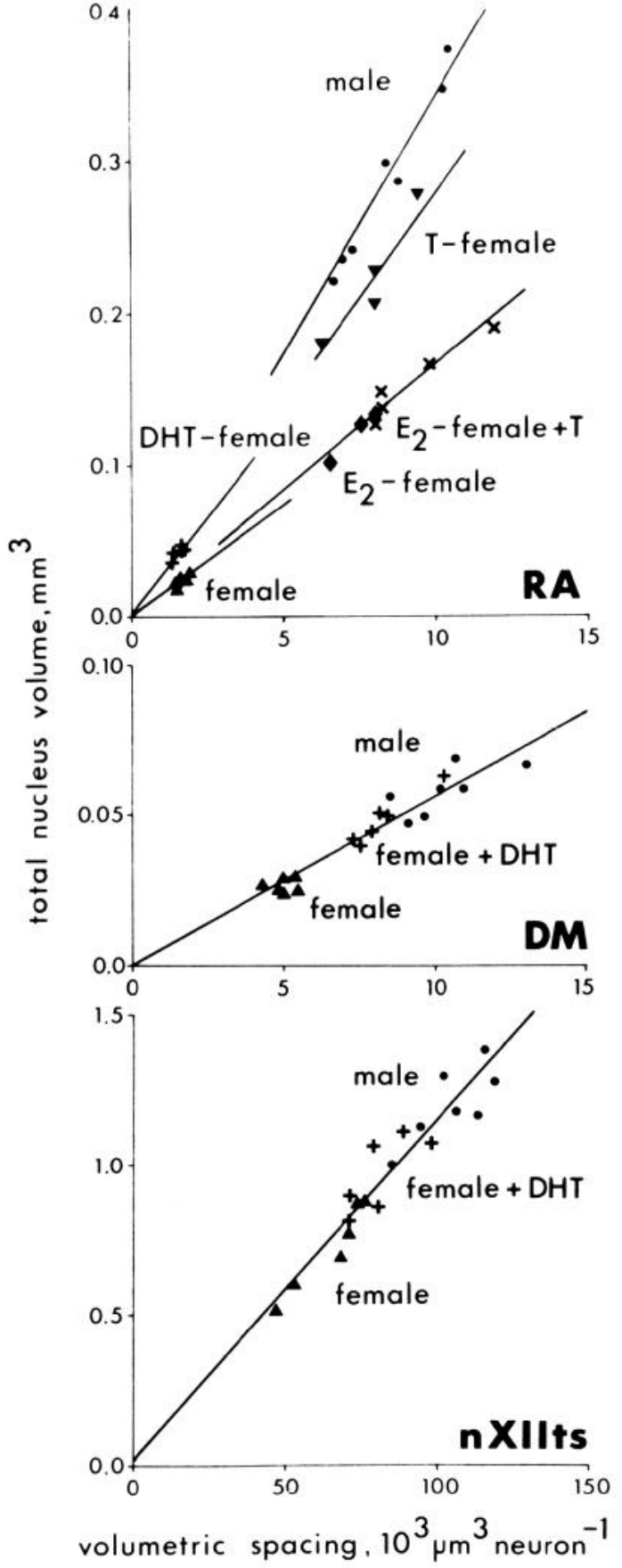

Figure 15. Graphs relating the total volumes of RA, DM, and nXIIts to the number and average volumetric spacing of their neuronal constituents. Note that the relationship of nucleus volume to average volumetric spacing per neuron is linear and that the slope of the line corresponds to the number of neurons in the nucleus. Exposure to either $\mathrm{E}_{2}$ or $\mathrm{T}$ at hatching produces an abrupt transition in the volumetric spacing of neurons within the female RA. In contrast, exposure to T or DHT in the adult exerts a graded influence upon the spacing of neurons within DM, nXIIts, or the RA of adult $\mathrm{E}_{2}$ females. Each data point represents one finch.

extreme sexual dimorphism of the system. Arnold (1978) has also provided evidence that microstimulation within HVc of both males and females is able to evoke electromyographic responses in the syrinx. Within RA, two qualitatively different types of neurons could be distinguished in Golgi-impregnated material from both normal males and females. Despite extreme sex differences in their size, the overall morphology of both types of neurons was remarkably similar. In RA at least, there is little evidence to suggest that gonadal hormones qualitatively re-specify the members of a neuronal population either with respect to the spectrum of neuronal types within the nucleus or in the pattern of their efferent projections. Instead, the overwhelming impression is that gonadal hormones influence quantitative aspects of a neuron's program for development which act to determine the extent of its dendritic arborization. A similar conclusion derives from work in canaries (DeVoogd and Nottebohm, 1981) and in hamsters (Greenough et al., 1977).

In quail, chickens, and pigeons, it has been argued that sexual differentiation depends upon the demasculinization of the female by endogenous production of estrogen (Adkins, 1978). With respect to the development of song in male zebra finches, a related paper shows that exposure to $E_{2}$ at hatching does not eliminate song nor demasculinize the sexual differentiation of the male's song system (Gurney, 1981). Instead, this report shows that both androgen and estrogen exert positive influences on indices of masculine sexual differentiation when administered to females.

Brain tissue has the capacity to aromatize $\mathrm{T}$ to $\mathrm{E}_{2}$ (Naftolin et al., 1975), and this is thought to be crucial for the androgen-dependent defeminization of lordosis behavior in rats (McEwen et al., 1977). Aromatase activity has also been detected in the telencephalon of Gallus domesticus (Callard et al., 1978). Masculinization of the cytoarchitecture of RA was induced by exposure to either $\mathrm{T}$ or $\mathrm{E}_{2}$ but not by DHT. Since DHT is not converted to $\mathrm{E}_{2}$ (Ryan, 1960), this suggests that aromatizable androgen is required for the masculinization of neuronal size in RA. Somal diameter could be used as a sensitive measure of the state of sexual differentiation of single neurons within RA, and it was shown that, above a certain threshold dose of $\mathrm{T}$ or $\mathrm{E}_{2}$, more than $95 \%$ of the neurons in RA are masculinized. As either the dose of $\mathrm{T}$ or the duration of exposure to $\mathrm{T}$ was decreased, the distribution of somal diameters for neurons within RA became bimodal. This indicates that RA neurons assumed one of two possible states: female or male. The parsimonious interpretation of these observations is that the transition of single neurons from a female to a male pathway of sexual differentiation is induced by exposure to $\mathrm{T}$ or $\mathrm{E}_{2}$. If we assume for the moment that the RA neurons are directly acted upon by $\mathrm{T}$ or $\mathrm{E}_{2}$, fractional differentiation of the neuronal population might result if the two types of neurons within RA (spinous and aspinous) differ with respect to their sensitivity to hormone. This is weakly argued against by the fact that the ratio of small to large neurons varied considerably among the sample of hormone-manipulated females. An alternative to distributed levels of hormone sensitivity among the RA neurons is that their transition from female to male is an inducerdependent, stochastic process much like that proposed for commitment to erythroid differentiation by Friend erythroleukemia cells (Gusella et al., 1976) and for commitment and fusion of myoblasts in vitro (Nadal-Ginard, 
1978). If so, the proportion of RA neurons which have undergone the transition from female to male would be expected to vary continuously with dose and with duration of exposure to inducer.

Together with the effects on neuronal size, early $T$ (M. E. Gurney, unpublished data) or $\mathrm{E}_{2}$ exposure renders a female capable of displaying song when primed with $\mathrm{T}$ or DHT as an adult (Gurney, 1981). Coincident with the induction of song, a second phase in the growth of $\mathrm{HVc}$ and RA is also initiated. However, androgen does not affect the volume of $\mathrm{HVc}$ or RA when administered to normal adult females. This observation is complementary to the sex difference in uptake of $\left[{ }^{3} \mathrm{H}\right]$ testosterone or its metabolites by cells within HVc reported by Arnold (1980b). Nearly 3 times as many labeled cells are observed in normal adult males as in females. Thus, two effects of early exposure to $\mathrm{T}$ or $\mathrm{E}_{2}$ are correlated with later behavioral capacity for androgen-dependent song, effects on neuronal size in the telencephalic song nuclei and induction of their ability to respond morphologically to androgen in the adult.

Studies of dendritic field maturation for cortical neurons from rats (Eayers and Goodhead, 1959), rabbits (Schade et al., 1964), and humans (Schade et al., 1962) show that the mean number of dendrites arising from the soma of pyramidal neurons matures very early. Since $\mathrm{E}_{2}$ influences the sexual differentiation of RA early in development but not in the adult (Gurney and Konishi, 1980; Gurney, 1981) and since determination of a neuron's number of dendritic arms is apparently also an early event, this suggests that an estrogen-specific mechanism might specify that spinous RA neurons elaborate a male, rather than female, number of dendritic arms. Since the frequency of branching is the same in both sexes, each additional dendritic arm should produce a stepwise increase in the amount of dendrite supported by a spinous RA neuron and, thus, a consequent stepwise increase in the volume of its dendritic field.

Androgen was also shown to act on stably differentiated song nuclei in the brainstem of normal adult females. Exposure to either $\mathrm{T}$ or DHT, but not to $\mathrm{E}_{2}$, elicits an increase in the volume of nXIIts and DM in adult females (Arnold, 1980a; Gurney and Konishi, 1980; Gurney, 1981) with no change in neuronal number. Thus, it would seem that androgen is able to act on the dendritic tree of fully differentiated neurons. Common to the effects of DHT upon RA (in adult $\mathrm{E}_{2}$ females) and DM or nXIIts was a graded increase in the average volumetric spacing of their constituent neurons. To the extent that neuritic outgrowth from sympathetic neurons in vitro applies to dendritic development by central neurons in vivo, the results of Bray (1970) suggest that new membrane is added only at the tips of neuronal processes rather than proximal to the soma. It may be that exposure to exogenous androgen similarly supports addition of dendrite to terminal (but not inner) branch segments of neurons in the adult song system.

Although females who were exposed to either $\mathrm{T}$ or $\mathrm{E}_{2}$ at hatching are able to sing, females who received $\mathrm{DHT}$ at hatching remain incapable of song (Gurney, 1981). This is despite the doubling of neuronal number in RA which is observed as a consequence of early DHT expo- sure. An influence of DHT on the volume of $\mathrm{HVc}$, with no change in its cytoarchitecture, is also observed (Gurney, 1981) and perhaps implies a similar influence of DHT on neuronal number in that nucleus as well. Nottebohm (1980) has presented evidence that the complexity of a canary's song shows a relationship with the volume of both RA and HVc, and this may imply that there might exist some difference between the complexity of the songs of $\mathrm{E}_{2}$ females as compared to those of $\mathrm{T}$ females or normal males. However, reversal of the sex difference of neuronal number in RA (and perhaps $\mathrm{HVc}$ ) does not influence the qualitative difference between the maleness (song) or femaleness (no song) of zebra finch vocal behavior.

The Golgi analysis and the neuroanatomical mapping studies provided no evidence that the sex difference in neuronal number within RA was due to the absence of a male-specific type of neuron from the female RA. If the RA neurons are the primary target of androgen action at hatching, then androgen might act as a mitogenic stimulus and enhance neuronal proliferation or else exposure to androgen might be permissive for the maintenance of RA neurons and decrease the amount of (putative) cell death within RA. Alternatively, since both efferent targets of RA, DM, and nXIIts respond specifically to androgen, it may be that effects on neuronal number in RA are mediated trans-synaptically. The target areas of neuronal populations are known to exert powerful effects upon their maintenance. When the target area of a neuronal population is removed, death of all of the neurons in the afferent population may result (Cowan and Clarke, 1976; Landmesser and Pilar, 1976). Increasing competition for the target also enhances cell death (Clarke and Cowan, 1975; Detwiler, 1920), while expanding the target field can reduce cell death (Hollyday and Hamburger, 1976). If the influence of androgen on neuronal number is mediated trans-synaptically, such an effect would be more subtle than a simple matching of neuronal number in RA to that in DM and nXIIts since the number of neurons in these nuclei is not sexually dimorphic. Instead, a trans-synaptic influence of androgen upon neuronal number might be mediated by the increase in neuronal size within DM and nXIIts which would have as its correlate an expansion in synaptic space or, alternatively, exposure to androgen might enhance the synthesis of a trophic factor(s) by these populations of neurons which would be permissive for the maintenance of RA neurons.

\section{Conclusions}

The paradigmatic preparation in which the role of soluble, extracellular signals during neural development has been explored is that of the superior cervical ganglion (SCG). In that preparation, progress was characterized by the discovery of an effect (enhanced neuritic outgrowth from the SCG in vitro when co-cultured with a mouse sarcoma) and identification of the soluble agent which elicited that effect (nerve growth factor); having that in hand, there then followed the exploration of its mode of action (extracellular versus intracellular? via a receptor? at the genomic level?) and of its cellular effects (trophic? instructive?). The chemical structures of gonadal hormones were characterized as early as 1930 and 
much has been learned about the molecular biology of their action on both somatic and neural tissues. Yet, since the realization in the 1940s that these steroids exert enduring effects upon the sexual differentiation of brain function, slow progress has been made in understanding the nature of their interactions with central neurons during development which are relevant to the later expression of adult sex differences in behavior. This has been due in large part to the extreme difficulty of tracing the relevant neural circuits through the tangle of the mammalian hypothalamus and preoptic area. As a preparation in which to investigate the action of steroid hormones, the advantage of the zebra finch has been the discrete nature of the song system and its clearly defined behavioral output. In the zebra finch, the cellular effects of early exposure to $\mathrm{T}$ or $\mathrm{E}_{2}$ on the telencephalic song nuclei are correlated with masculinization of the system's behavioral capacity for song. Within RA, these two hormones seemingly act to instruct the transition of single neurons from a female to a male pathway of sexual differentiation. This has as its result the masculinization of neuronal size and of the ability of the telencephalic song nuclei to respond to androgen (both morphologically and behaviorally) in the adult.

\section{References}

Adkins, E. K. (1978) Sex steroids and the differentiation of avian reproductive behavior. Am. Zool. 18: 501-509.

Arnold, A. P. (1974) Behavioral effects of androgen on zebra finches (Poephila guttata) and a search for its sites of action. Ph.D. dissertation, Rockefeller University, New York.

Arnold, A. P. (1980a) Effects of androgen on the volumes of sexually dimorphic brain regions in the zebra finch. Brain Res. 185: 441-444.

Arnold, A. P. (1980b) Quantitative analysis of sex differences in hormone accumulation in the zebra finch brain: Methodological and theoretical issues. J. Comp. Neurol. 165: 421-436.

Arnold, A. P., F. Nottebohm, and D. W. Pfaff (1976) Hormone concentrating cells in vocal control areas and other areas in the brain of the zebra finch (Poephila guttata). J. Comp. Neurol. 165: 487-493.

Bray, D. (1970) Surface movements during the growth of single explanted neurons. Proc. Natl. Acad. Sci. U. S. A. 65: 905910.

Breedlove, S. M., and A. P. Arnold (1980) Hormone accumulation in a sexually dimorphic motor nucleus of the rat spinal cord. Science 210: 564-566.

Caleresu, F. R., and J. L. Henry (1971) Sex difference in the number of sympathetic neurons in the spinal cord of the cat. Science 173: 343-344.

Callard, G. V., Z. Petro, and K. J. Ryan (1978) Conversion of androgen to estrogen and other steroids in the vertebrate brain. Am. Zool. 18: 511-523.

Cammermeyer, J. (1967) Artifactual displacement of neuronal nucleoli in paraffin sections. J. Hirnforsch. 9: 209-224.

Campenot, R. B. (1977) Local control of neurite development by NGF. Proc. Natl. Acad. Sci. U. S. A. 74: 4516-4519.

Clarke, P. G. H., and W. M. Cowan (1975) Ectopic neurons and aberrant connections during neural development. Proc. Natl. Acad. Sci. U. S. A. 72: 4455-4458.

Cowan, W. M., and P. G. H. Clarke (1976) The development of the isthmo-optic nucleus. Brain Behav. Evol. 13: 345-375.

Cowan, W. M., D. I. Gottleib, A. Hendrickson, J. L. Price, and T. A. Woolsey (1972) The autoradiographic demonstration of axonal connections in the central nervous system. Brain Res. 37: $21-51$.
Detwiler, S. R. (1920) On the hyperplasia of nerve centers resulting from excessive peripheral loading. Proc. Natl. Acad. Sci. U. S. A. 6: 96-101.

DeVoogd, T. J., and F. Nottebohm (1981) Sex differences in dendritic morphology of a song control nucleus in the canary: A quantitative Golgi study. J. Comp. Neurol. 196: 309-316.

Dyer, R. G., N. K. MacLeod, and F. Ellendorff (1976) Electrophysiological evidence for sexual dimorphism and synaptic convergence in the preoptic and anterior hypothalamic areas of the rat. Proc. R. Soc. Lond. (Biol.) 193: 421-440.

Eayers, J. T., and B. Goodhead (1959) Postnatal development of the cerebral cortex of the rat. J. Anat. 93: 385-402.

Gorski, R. A., J. H. Gordon, J. E. Shryne, and A. M. Southam (1978) Evidence for a morphological sex difference within the preoptic area of the rat brain. Brain Res. 148: 333-346.

Goy, R. W., and B. S. McEwen (1980) Sexual Differentiation of the Brain, MIT Press, Cambridge, MA.

Green, L. A., and A. S. Tischler (1976) Establishment of a noradrenergic clonal line of rat adrenal pheochromocytoma cells which respond to nerve growth factor. Proc. Natl. Acad. Sci. U. S. A. 73: 2424-2428.

Greenough, W. T., C. S. Carter, C. Steerman, and T. J. DeVoogd (1977) Sex differences in dendritic patterns in hamster preoptic area. Brain Res. 126: 63-72.

Gurney, M. E. (1981) Behavioral correlates of sexual differentiation in the zebra finch song system. Brain Res., in press.

Gurney, M. E., and M. Konishi (1980) Hormone induced sexual differentiation of brain and behavior in zebra finches. Science 208: 1380-1382.

Gusella, J., R. Geller, B. Clarke, V. Weeks, and D. Housman (1976) Commitment to erythroid differentiation by Friend erythroleukemia cells: A stochastic analysis. Cell 9: 221-229.

Hollyday, M., and V. Hamburger (1976) Reduction of naturally occurring motor loss by enlargement of the periphery. $J$. Comp. Neurol. 170: 311-320.

Konigsmark, B. W. (1970) The counting of neurons. In Contemporary Research Methods in Neuroanatomy, W. J. H. Nauta and S. O. Ebbeson, eds., pp. 315-340, Springer-Verlag, New York.

Landmesser, L., and G. Pilar (1976) Fate of ganglion cell synapses and ganglion cell axons during normal and induced cell death. J. Cell Biol. 68: 357-374.

Letourneau, P. C. (1978) Chemotactic response of nerve fiber elongation to nerve growth factor. Dev. Biol. 66: 183-196.

Levi-Montalcini, R., and P. V. Angeletti (1968) Nerve growth factor. Physiol. Rev, 48: 534-569.

Ling, F. A., J. A. Patterson, A. Privat, S. Mori, and C. P. LeBlond (1973) Investigation of glial cells in semithin sections. J. Comp. Neurol. 149: 43-72.

Lund, J. S. (1973) Organization of neurons in the visual cortex, area 17, of the monkey. J. Comp. Neurol. 159: 305-344.

Lynch, G., C. Gall, P. Mensah, and C. Cotman (1974) Horseradish peroxidase histochemistry: A new method of tracing efferent projections in the central nervous system. Brain Res. 65: $373-380$

McEwen, B. S., I. Leiberburg, N. Maclusky, and L. Plapinger (1977) Do estrogen receptors play a role in the sexual differentiation of the brain? J. Steroid Biochem. 8: 593-601.

Menesini-Chen, M. G., J. S. Chen, and R. Levi-Montalcini (1978) Sympathetic nerve fibers in growth in the central nervous system of the neonatal rat upon intracerebral NGF injections. Arch. Ital. Biol. 116: 53-84.

Mesulam, M.-M. (1978) Tetramethyl benzidine for horseradish peroxidase neurohistochemistry: A non-carcinogenic blue reaction product with superior sensitivity for visualizing neural afferents and efferents. J. Histochem. Cytochem. 26: 106-117.

Mudge, A. W. (1979) Somatostatin and substance P levels in cultured sensory neurons are influenced by environmental factors. Soc. Neurosci. Abstr. 5: 1803. 
Nadal-Ginard, B. (1978) Commitment, fusion and biochemical differentiation of a myogenic cell line in the absence of DNA synthesis. Cell 15: 855-864.

Naftolin, F., J. Ryan, I. J. Davies, V. V. Reddy, F. Flores, Z. Petro, R. J. White, Y. Takaoka, and L. Wolin (1975) The formation of estrogen by central neuroendocrine tissues. Recent Prog. Horm. Res. 31: 295-319.

Nottebohm, F. (1980) Brain space for a learned task. Brain Res., in press.

Nottebohm, F., and A. P. Arnold (1976) Sexual dimorphism in vocal control areas of the song bird brain. Science 194: 211213.

Nottebohm, F., and D. B. Kelley (1978) Projections to vocal control nuclei of the canary telencephalon. Soc. Neurosci. Abstr. 4: 296.

Nottebohm, F., T. M. Stokes, and C. M. Leonard (1976) Central control of song in the canary Serinus canarius. J. Comp. Neurol. 165: 457-486.

Patterson, P. H., and L. Y. C. Chun (1977) The induction of acetylcholine synthesis in primary cultures of dissociated rat sympathetic neurons. Dev. Biol. 56: 263-280.

Phoenix, C. W., R. W. Goy, A. A. Gerall, and W. C. Young (1959) Organizing action of prenatally administered testosterone proprionate on the tissues mediating mating behavior in the female guinea pig. Endocrinology 65: 369-382.

Pröve, E. (1974) Der Einfluss von Kastration und Testosteronsubstitution auf das Sexualverhalten männlicher Zebrafinken. J. Ornithol. 115: 338-347.

Prove, E. (1978) Quantitative Untersuchungen zur Wechselbeziehungen Zwischen Balzaktivität und Testosterontiteron bei männlichen Zebrafinken. Z. Tierpsychol. 48: 47-67.

Raisman, G., and P. M. Field (1973) Sexual dimorphism in the neuropil of the preoptic area of the rat and its dependence on neonatal androgen. Brain Res. 54: 1-29.

Ramon-Moliner, E. (1970) The Golgi-Cox technique. In Contemporary Research Methods in Neuroanatomy, W. J. H. Nauta and S. O. Ebbeson, eds., pp. 32-52, Springer-Verlag, New York.

Ryan, K. J. (1960) Estrogen formation by the human placenta: Studies on the mechanism of steroid aromatization by mammalian tissue. Acta Endocrinol. Copenh. Suppl. 51, 35: 697698.

Schade, J. P., K. Meeter, and W. B. von Groeningen (1962) Maturational aspects of the dendrites in human cerebral cortex. Acta Morphol. Neerl. Scand. 5: 37-48.

Schade, J. P., H. van Backer, and E. Colon (1964) Quantitative analysis of neuronal parameters in the maturing cerebral cortex. Prog. Brain Res. 4: 150-175.

Sholl, D. A. (1954) Dendritic organization in the neurons of the visual and motor cortices of the cat. J. Anat. 87: 387-407.

Siegel, S. (1956) Nonparametric Statistics for the Behavioral Sciences, McGraw-Hill Book Co., New York.

Toran-Allerand, C. D. (1976) Sex steroids and the development of the newborn mouse hypothalamus and preoptic area in vitro: Implications for sexual differentiation. Brain Res. 106: 407-412.

Zeier, H., and H. J. Karten (1971) The archistriatum of the pigeon: Organization of afferent and efferent connections. Brain Res. 31: 313-326. 